\title{
HYDRAULICS LAB MANUAL
}

Shiblu Sarker

MARCH 19, 2021 


\begin{abstract}
Hydraulics provides a foundation for students who specialize in the field of Water Resources Engineering. This lab manual will deal with application of basic principles of fluids at rest and in motion for analysis and design of hydraulic systems and will provide an advanced understanding of fluid mechanics, open channel flow, pipe flow, water pumps, and some engineering applications of these concepts. This lab manual is the basic laboratory procedure of fluid movement in pipes and open channel. This Lab will implement an active learning laboratory environment to assess students' understanding and while covering experiments of pipe and open channel flow. Practical engineering problems and design applications will be emphasized.
\end{abstract}




\section{Table of Contents}

ABSTRACT

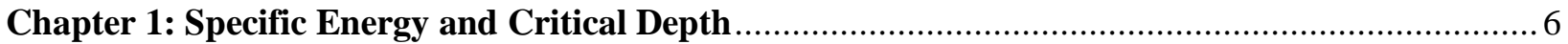

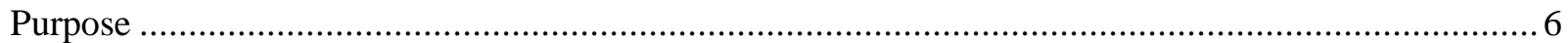

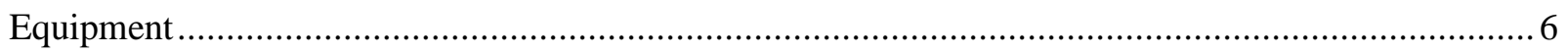

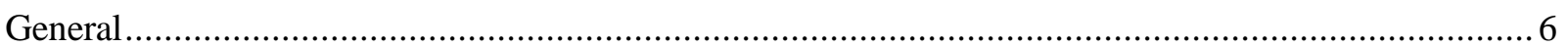

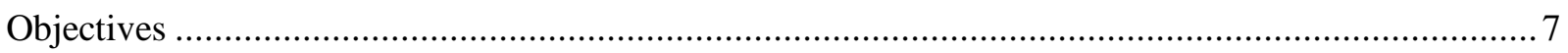

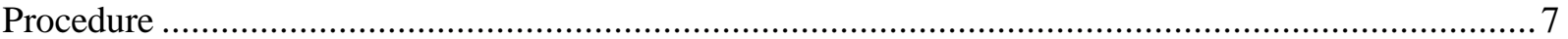

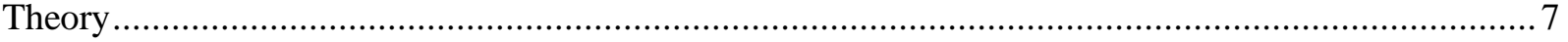

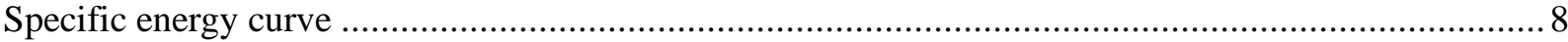

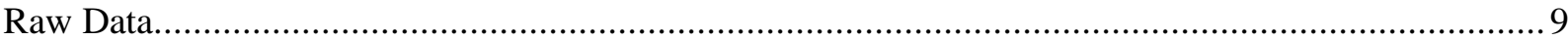

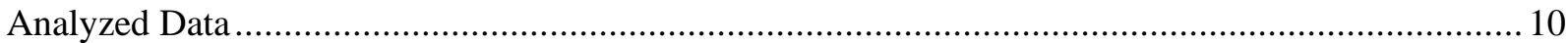

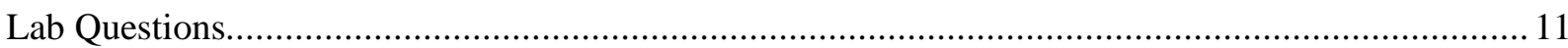

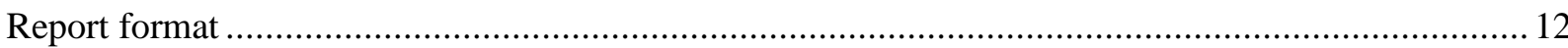

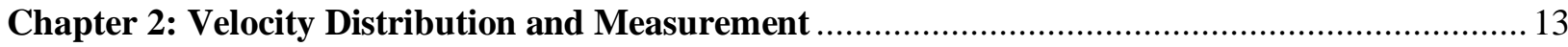

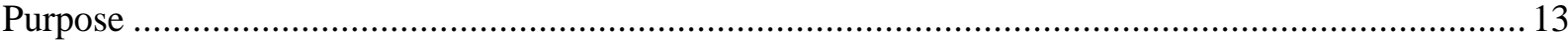

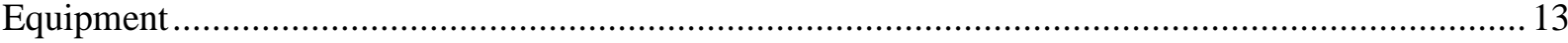

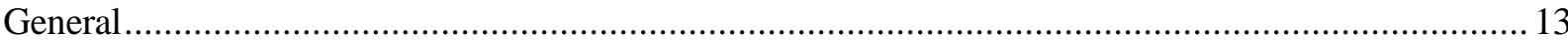

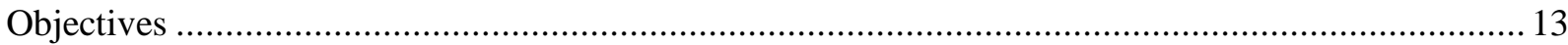

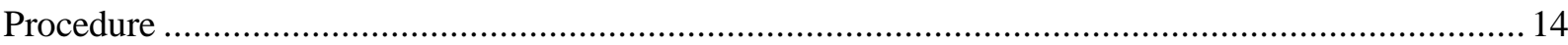

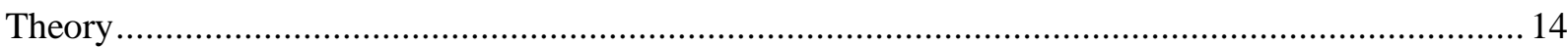

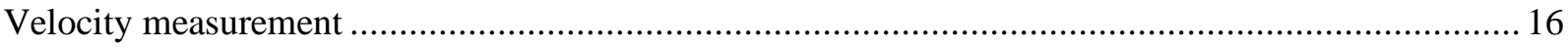

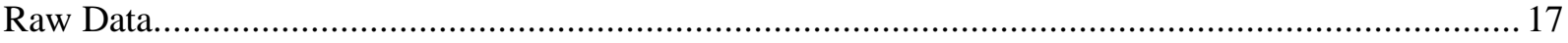

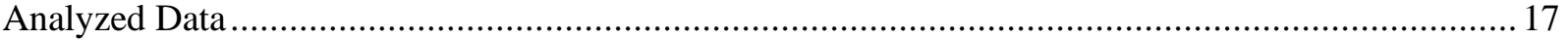

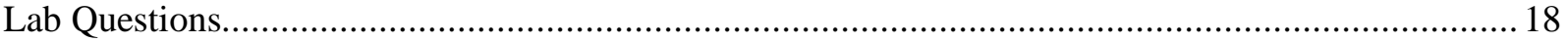

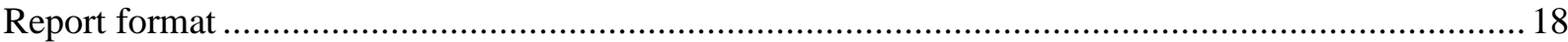

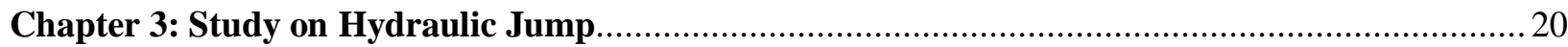

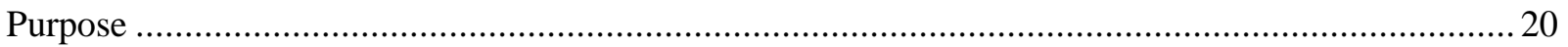

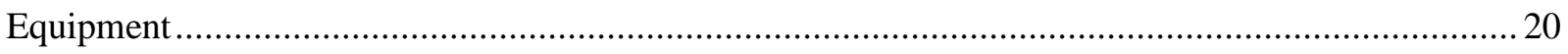

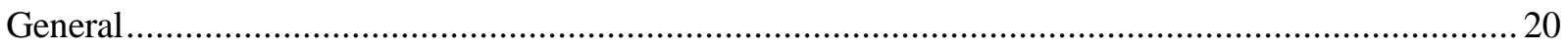

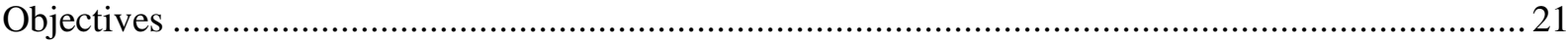

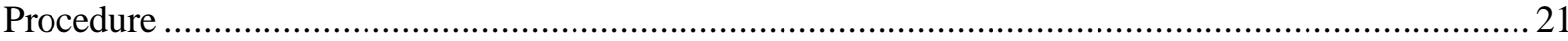

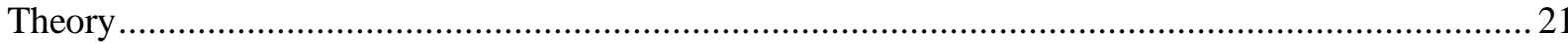




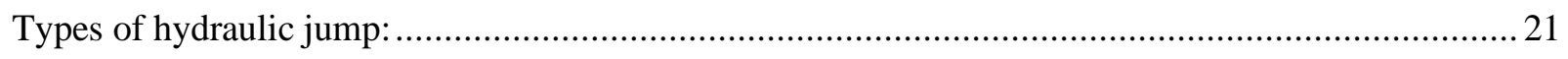

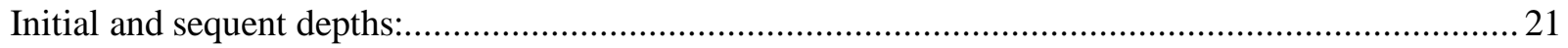

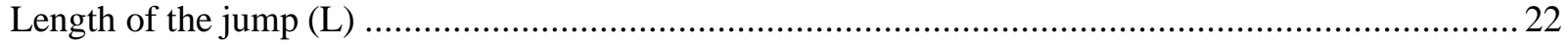

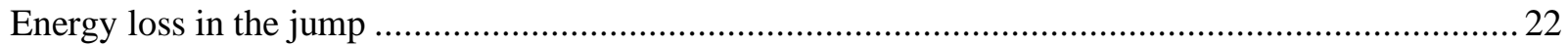

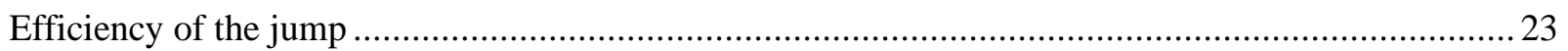

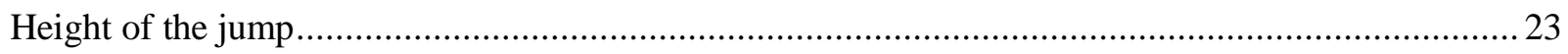

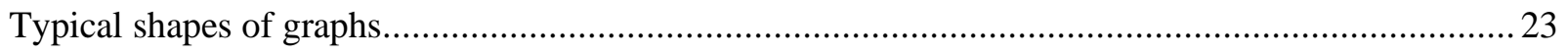

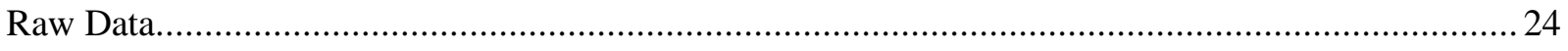

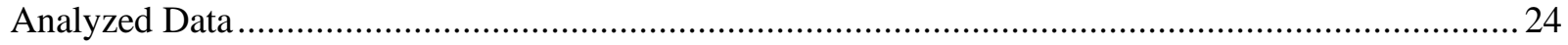

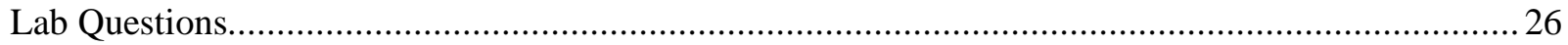

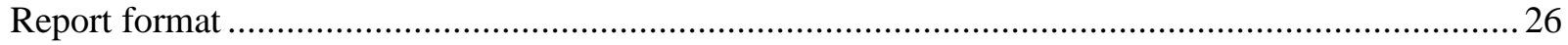

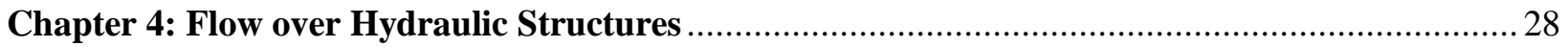

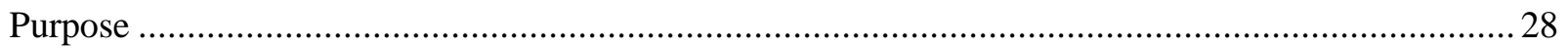

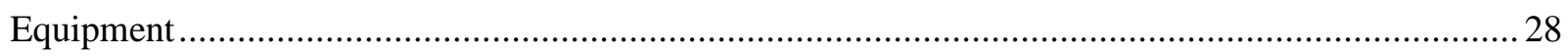

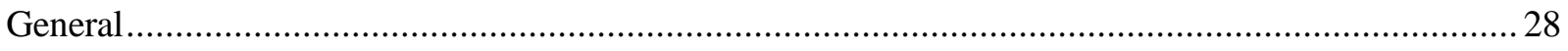

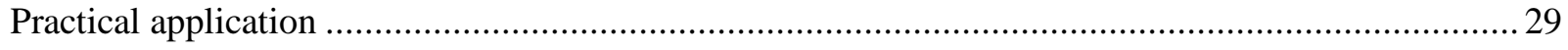

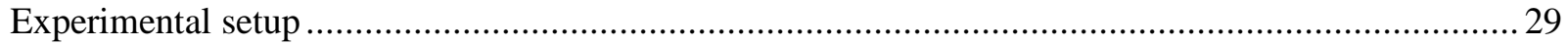

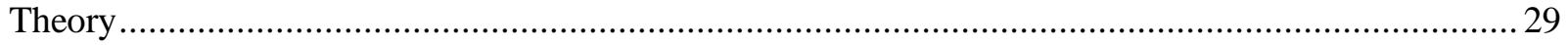

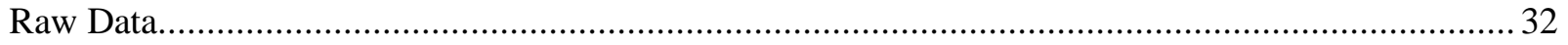

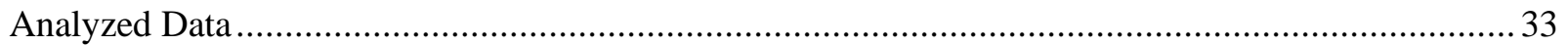

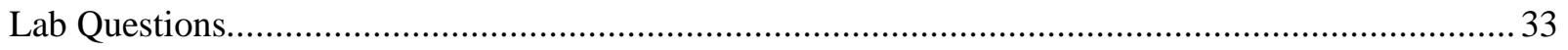

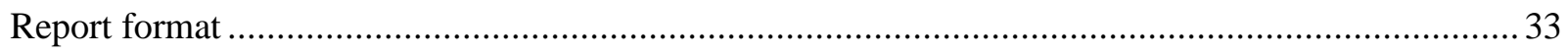

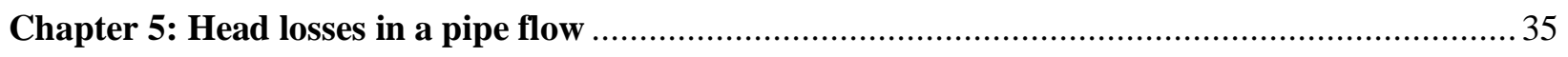

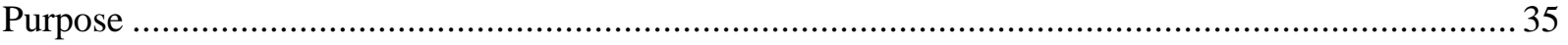

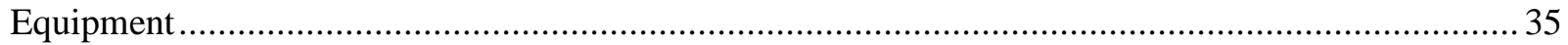

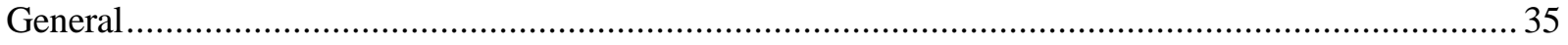

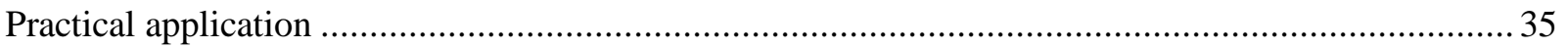

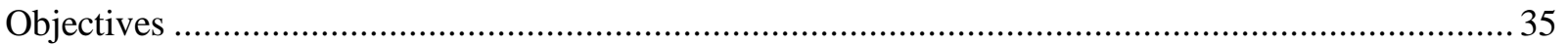

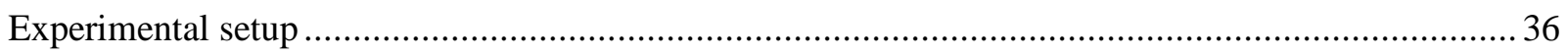

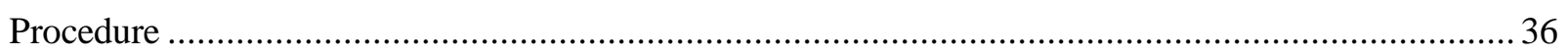

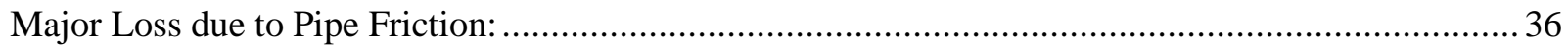

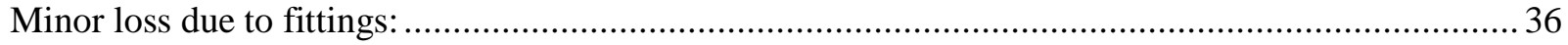

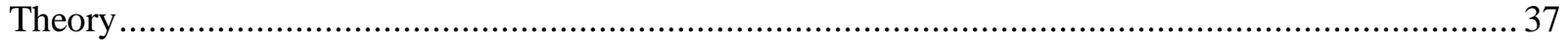




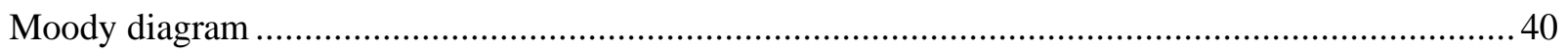

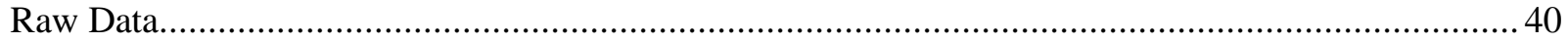

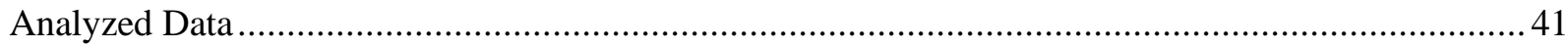

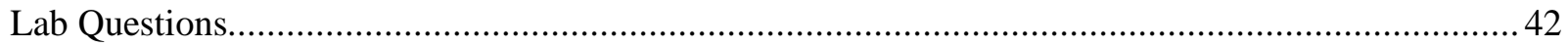

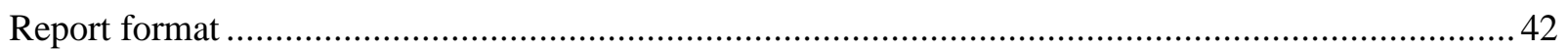

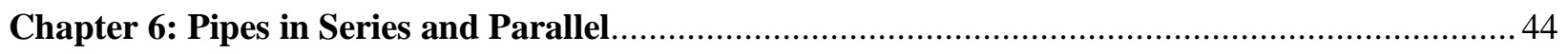

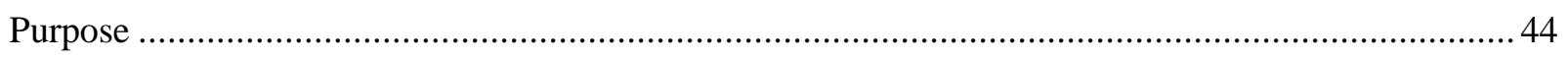

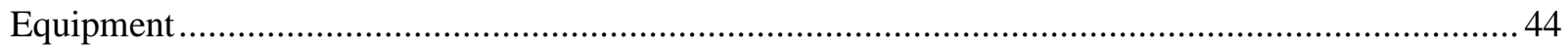

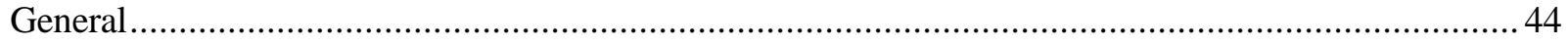

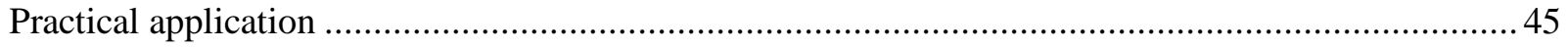

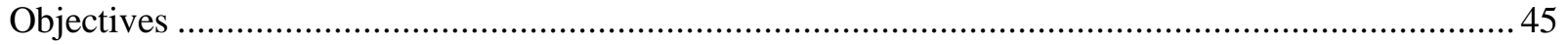

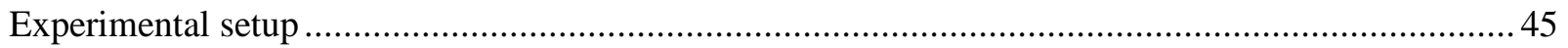

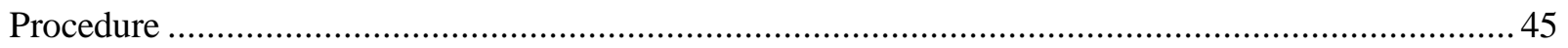

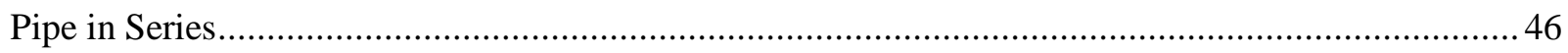

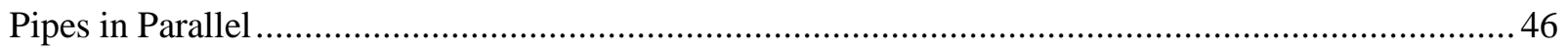

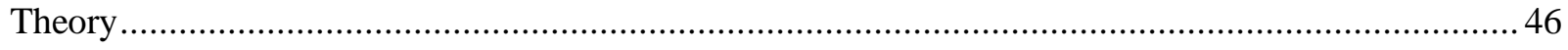

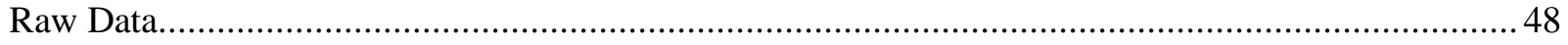

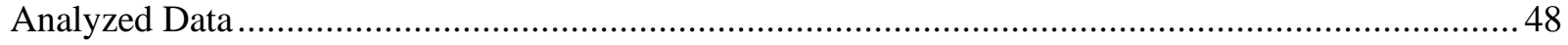

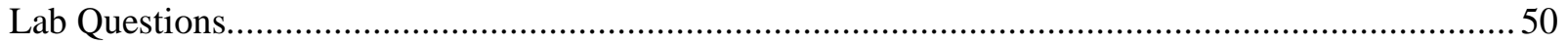

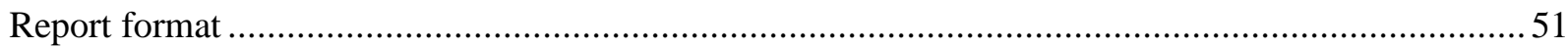

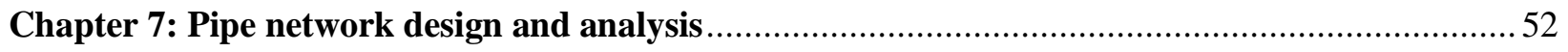

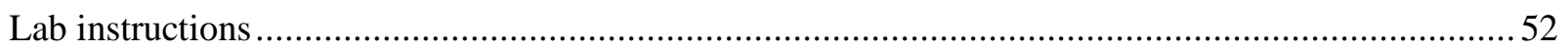

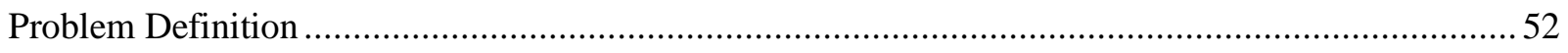

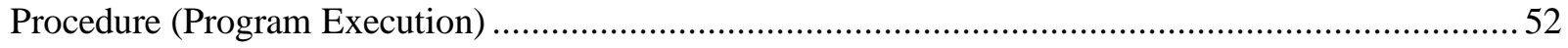

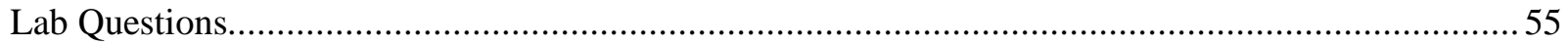

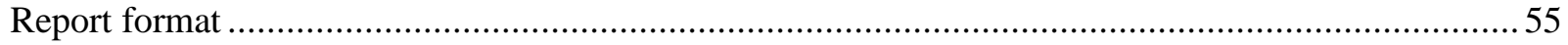

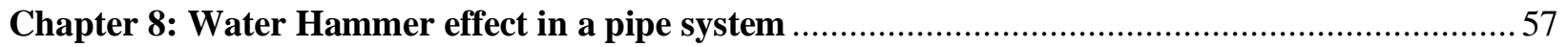

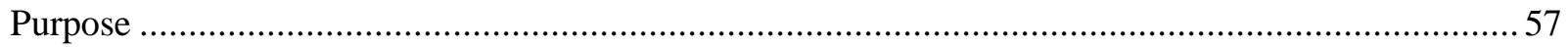

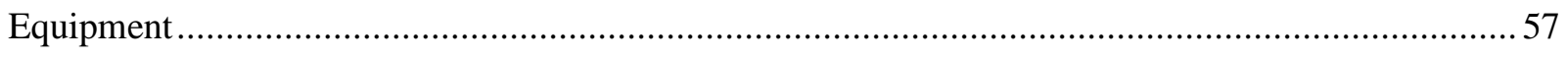

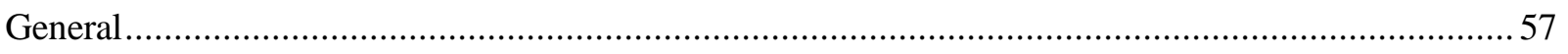

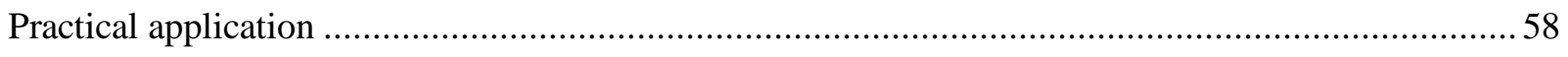

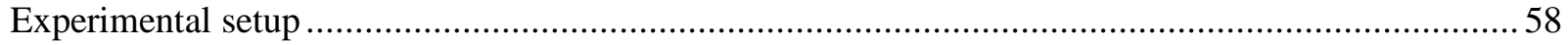

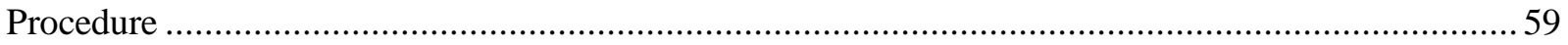




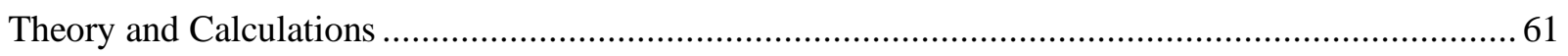

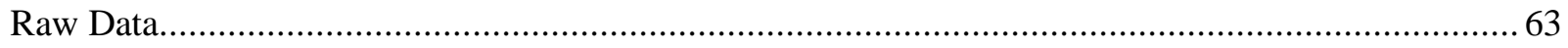

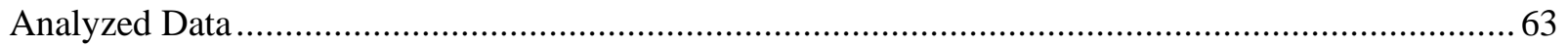

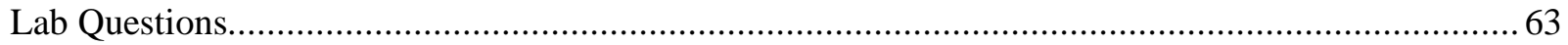

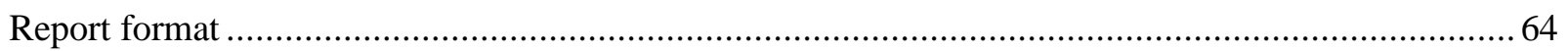




\section{Chapter 1: Specific Energy and Critical Depth}

Purpose

The purpose of this experiment is to derive the specific energy equation and to show that the critical depth is a function of the flow per width.

\section{Equipment}

1. S16 Armfield Hydraulic Flow Demonstrator

2. Stopwatch

\section{General}

The concept of specific energy is extremely useful in the solution of many problems in open channel flow. This experiment deals with the development of specific energy curves. These curves are useful in determining the state of flow in a channel, i.e., whether the flow is critical, subcritical, or supercritical. Flow is critical when the Froude number is equal to unity. When the depth of flow is above the critical depth, the subcritical state of flow exists in the channel. When the depth of flow is below the critical depth, the supercritical state of flow exists. Also, the critical state of flow gives us several important conditions, such as, the specific energy is minimum for a given depth.

When the flow is dominated by the gravity, then the type of flow can be identified by a dimensionless number, known as Froude Number. Given by:

$$
F r=\frac{v}{\sqrt{g D}}
$$

Where, $v$ is the mean velocity of flow, $D$ is the hydraulic depth $(D=A / T=y$ for wide rectangular channel), $A$ is the cross-sectional area, $T$ is the top width and $g$ is the acceleration due to gravity. Depending on the effect of gravity relative to inertia, the flow may be subcritical, critical or supercritical-

$$
\begin{gathered}
\text { When, } F r<1 \text { the flow is subcritical } \\
F r=1 \text { the flow is critical } \\
F r>1 \text { the flow is supercritical. }
\end{gathered}
$$

All these conditions are used in designing the various types of transitions and in controlling the flow using different control structures, for example, in determining the height of a weir, the width of a flume, opening of sluice gate, etc. For details please see (Sarker, 2021a). 


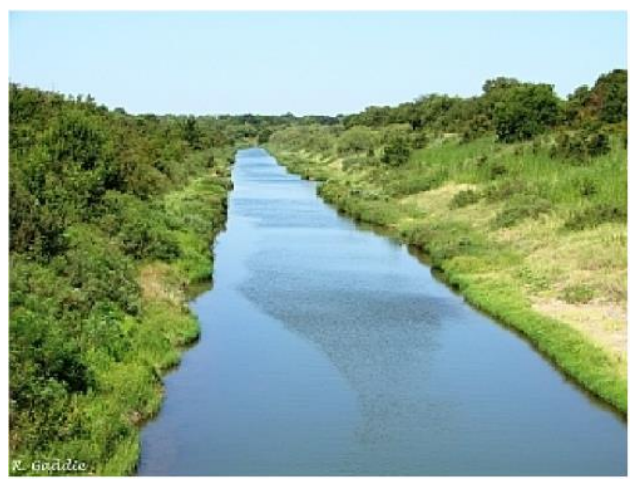

Fig 1. Open channel flow

\section{Objectives}

1. To develop the specific energy curve.

2. To determine critical depth $\left(y_{c}\right)$.

3. To determine the state of flow.

4. To observe the subcritical and the supercritical flows.

\section{Procedure}

1. Adjust the height of the sluice gate $y_{g}=10 \mathrm{~mm}$ above the bed.

2. Gradually open the flow control valve to reach a depth of $y_{0}=170 \mathrm{~mm}$ at the upstream side of the gate.

3. Measure and record the inflow rate $(\mathrm{Q})$.

4. Without changing the inflow, raise the gate in $5 \mathrm{~mm}$ increments until $y_{g}=25 \mathrm{~mm}$ and for each value of $y_{g}$, record $y_{0}$ and $y_{1}$.

5. Repeat steps (1 to 4 ), for a different flow, $\mathrm{Q}$ (so that $y_{0}=150 \mathrm{~mm}$ ). It should be noted that $y_{0}$ can be adjusted by changing the inflow rate.

\section{Theory}

Energy conservation is an important concept when analyzing open channel flows. If we consider the datum located at the bottom of the channel, the energy in each section is calculated based on the following equation:

$$
E=y+\frac{v^{2}}{2 g}
$$

In this equation, $v$ is velocity, $y$ is depth and $g$ is acceleration due to gravity.

In a rectangular channel (width $=\mathrm{b}$ ) with an inflow rate of $\mathrm{Q}$ the energy can be calculated using the following equation: 


$$
E=y+\frac{Q^{2}}{2 g b^{2} y^{2}}
$$

For given values of discharge, $Q$, a specific energy diagram depicting energy and the depth of water, $y$, can be developed. The specific energy is the energy above the datum, which we have chosen as the bottom of the channel.

For each value of unit discharge, there is an associated critical depth, $y_{c}$. Flow travelling at a depth greater than the critical depth is subcritical, and flow travelling at a depth less than the critical depth is supercritical. The critical depth is the smallest energy value. Therefore, we can take the first derivative of the energy equation with respect to depth to determine the critical depth ( $d E / d y)$ and equate it to zero to determine the minimum value. For details please see (Sarker, 2021a).

$$
\begin{gathered}
\frac{d E}{d y}=0 \\
\frac{d}{d y}\left(y+\frac{Q^{2}}{2 g b^{2} y^{2}}\right)=0 \\
1+\frac{d}{d y}\left\{\frac{Q^{2}}{2 g b^{2}}\left(\frac{1}{y^{2}}\right)\right\}=0 \\
1+\frac{Q^{2}}{2 g b^{2}} \frac{d}{d y}\left\{\left(y^{-2}\right)\right\}=0 \\
1-\frac{2 Q^{2}}{2 g b^{2}} \frac{1}{y_{c}{ }^{3}}=0 \\
1=\frac{2 Q^{2}}{2 g b^{2}} \frac{1}{y_{c}{ }^{3}} \Rightarrow y_{c}=\sqrt[3]{\frac{Q^{2}}{g b^{2}}}
\end{gathered}
$$

Specific energy curve

Specific energy curve shown in Fig. 2. 


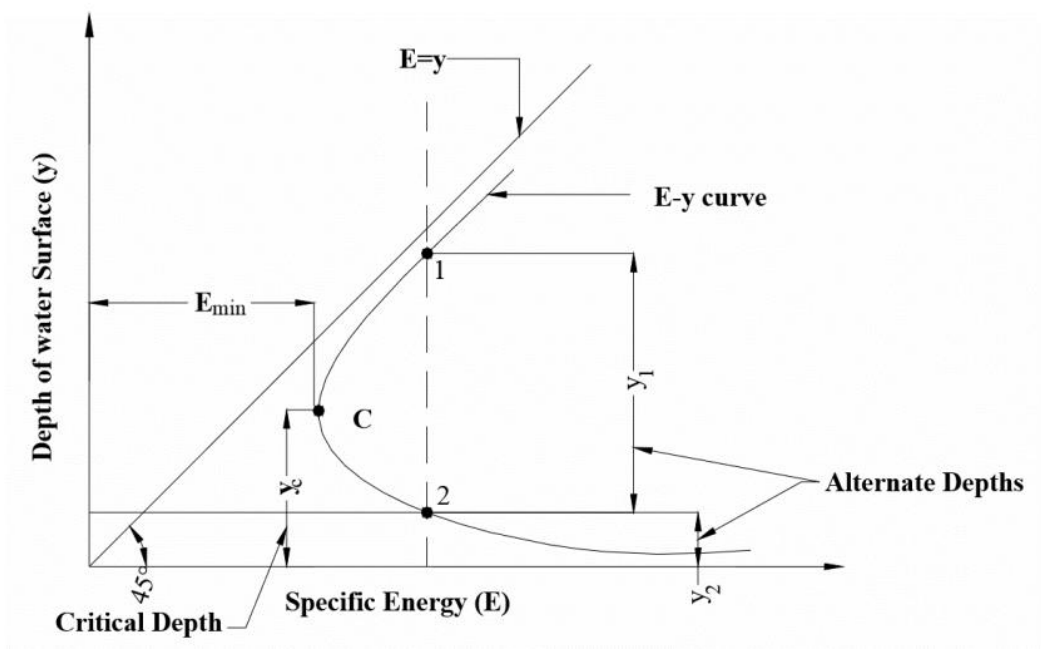

Fig 2. Specific Energy Curve for a given discharge

\section{Raw Data}

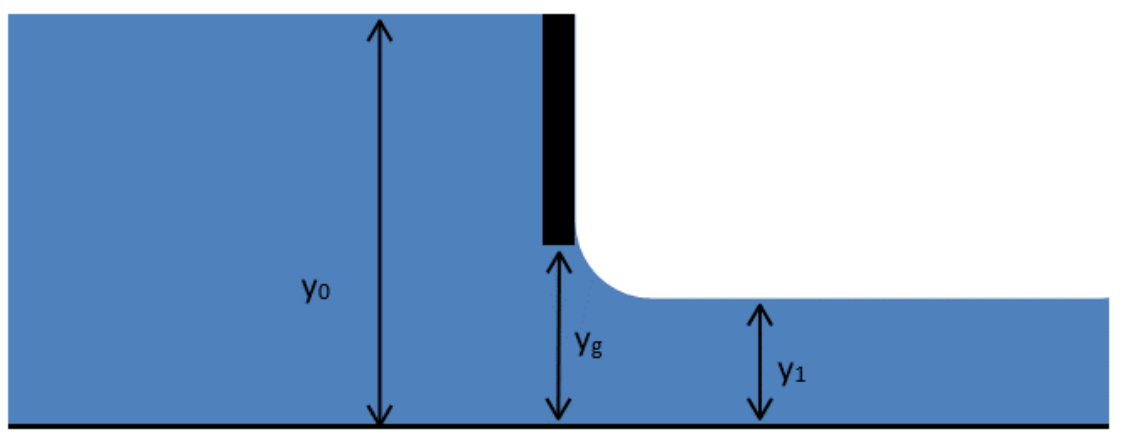

Fig 3. Experimental data measurement

Record the depths at the upstream and downstream sections of the gate and the streamflow. Then, fill in the following tables.

Table 1 - Initial $y_{0}=170 \mathrm{~mm}, \mathrm{t}=$ $\mathrm{s}, \mathrm{V}=20 \mathrm{~L}$

\begin{tabular}{|c|c|c|c|}
\hline & $y_{g}(\mathrm{~mm})$ & $y_{0}(\mathrm{~mm})$ & $y_{1}(\mathrm{~mm})$ \\
\hline 1 & 10 & 170 & \\
\hline 2 & 15 & & \\
\hline 3 & 20 & & \\
\hline 4 & 25 & & \\
\hline
\end{tabular}


Table 2 - Initial $y_{0}=150 \mathrm{~mm}, \mathrm{t}=$ $\mathrm{s}, \mathrm{V}=20 \mathrm{~L}$

\begin{tabular}{|c|c|c|c|}
\hline & $y_{g}(\mathrm{~mm})$ & $y_{0}(\mathrm{~mm})$ & $y_{1}(\mathrm{~mm})$ \\
\hline 1 & 10 & 150 & \\
\hline 2 & 15 & & \\
\hline 3 & 20 & & \\
\hline 4 & 25 & & \\
\hline
\end{tabular}

\section{Analyzed Data}

Using all the data collected in the previous step and for each value of Q, fill in the following tables:

Table 3 - Initial $y_{0}=170 \mathrm{~mm}, \mathrm{Q}=$ $m m^{3} / s$

\begin{tabular}{|c|c|c|c|c|c|c|}
\hline & $y_{g}(\mathrm{~mm})$ & $y_{0}(\mathrm{~mm})$ & $y_{1}(\mathrm{~mm})$ & $E_{0}(\mathrm{~mm})$ & $E_{1}(\mathrm{~mm})$ & \multirow{2}{*}{$y_{c}(\mathrm{~mm})$} \\
\hline 1 & 10 & & & & & \\
\hline 2 & 15 & & & & & \\
\hline 3 & 20 & & & & & \\
\cline { 1 - 5 } 4 & 25 & & & & & \\
\hline
\end{tabular}

Table 4 - Initial $y_{0}=150 \mathrm{~mm}, \mathrm{Q}=$ $m m^{3} / s$

\begin{tabular}{|c|c|c|c|c|c|c|}
\hline & $y_{g}(\mathrm{~mm})$ & $y_{0}(\mathrm{~mm})$ & $y_{1}(\mathrm{~mm})$ & $E_{0}(\mathrm{~mm})$ & $E_{1}(\mathrm{~mm})$ & $y_{c}(\mathrm{~mm})$ \\
\hline 1 & 10 & & & & & \\
\hline 2 & 15 & & & & & \\
\hline 3 & 20 & & & & & \\
\hline 4 & 25 & & & & & \\
\hline
\end{tabular}


Using the data, compute the following:

1. For each discharge value, sort the data in descending order of depth, $\mathrm{Y}$ and fill in the following tables.

2. Plot the (y-E) line for two different inflows in one graph.

3. Estimate the critical depth based on the specific energy curves.

Table 5 - Initial $y_{0}=170 \mathrm{~mm}, \mathrm{Q}=$ $\mathrm{mm}^{3} / \mathrm{s}$

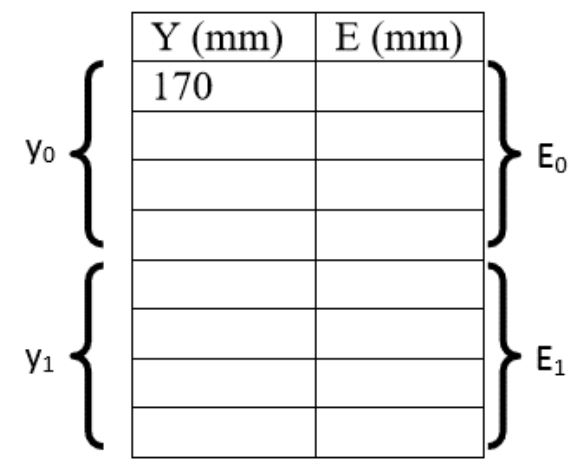

Table 6 - Initial $y_{0}=150 \mathrm{~mm}, \mathrm{Q}=$ $m m^{3} / s$

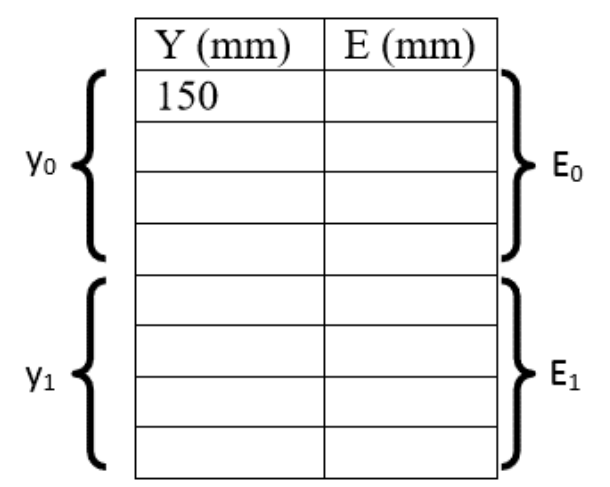

\section{Lab Questions}

1. Why the state of flow and the critical depth of a river or canal need to be determined?

2. How is the critical depth affected by $\mathrm{Q}$ ?

3. Theoretically, what should be the relation between $E_{0}$ and $E_{1}$ ? Do the calculated values agree with the theory?

4. Do the calculated values of critical depth agree with the corresponding values extracted from the plotted curves? If not, explain why. 


\section{Report format}

Students are expected to submit the lab report in the following format. Report will be evaluated in $100 \%$. The distribution of total marks is shown in bracket in the table below. Please submit a soft copy (pdf) in the webcourse assignment section. You can send any questions regarding Lab by webcourses inbox. Please prepare a pdf file in the following format and mention the course number in the subject line.

"CWR4202CLab-LastName-FirstName-Labno.pdf" (For example, CWR4202CLab-Sarker Shiblu-Lab01.pdf)

\begin{tabular}{|l|l|l|}
\hline & Cover Page & $\begin{array}{l}\text { Please provide the course number, course name, experiment name, } \\
\text { your name and submission date. }\end{array}$ \\
\hline 1 & Introduction (5\%) & $\begin{array}{l}\text { Not more than } 200 \text { words. It may include the background and scope } \\
\text { of the experiment. }\end{array}$ \\
\hline 2 & Objective (5\%) & Please formulate the main objective (goal, aim) of the experiment. \\
\hline 3 & Procedure (5\%) & $\begin{array}{l}\text { Please provide step by step procedure how the experiment can be } \\
\text { done. }\end{array}$ \\
\hline 4 & $\begin{array}{l}\text { Experimental data } \\
(10 \%)\end{array}$ & $\begin{array}{l}\text { Please present the raw data in tabular format mentioning the proper } \\
\text { unit and symbol. }\end{array}$ \\
\hline 5 & $\begin{array}{l}\text { Sample calculation } \\
(20 \%)\end{array}$ & $\begin{array}{l}\text { In this section, please present the calculation of different parameters } \\
\text { from the experimental data along with mathematical equations } \\
\text { provided in the manual. }\end{array}$ \\
\hline 6 & Results (15\%) & $\begin{array}{l}\text { Please present your results in tabular format. If it is required to } \\
\text { present it by graph, chart etc., please put those in this section. }\end{array}$ \\
\hline 7 & $\begin{array}{l}\text { Answer to the lab } \\
\text { questions (20\%) }\end{array}$ & $\begin{array}{l}\text { Please provide the answers to the lab questions. Please try to answer } \\
\text { what is asked for. }\end{array}$ \\
\hline 8 & Discussion (15\%) & $\begin{array}{l}\text { In this part, please discuss your results. If any kind of error, unusual } \\
\text { results etc. are found, please discuss it in this section. Try to be } \\
\text { precise and write to the point which is asked for. Also write the } \\
\text { practical value of the experiment. }\end{array}$ \\
\hline 9 & Conclusions (5\%) & \begin{tabular}{l} 
Please write a short conclusion (not more than 50 words). \\
\hline
\end{tabular} \\
\hline
\end{tabular}




\section{Chapter 2: Velocity Distribution and Measurement}

\section{Purpose}

The purpose of this experiment is to measure the velocity in the working section using Pitot tube and manometer and to compare it with the actual value. Having known the total pressure in two points in a specific section of channel, the velocity can be calculated using the Bernoulli equation.

Equipment

1. S16 Armfield Hydraulic Flow Demonstrator

2. Stopwatch

3. Pitot tube

\section{General}

Velocity of flow is an important parameter in open channel flow. In order to find out the channel discharge, the velocity distribution needs to be known. In an open channel the velocity is not uniform over the cross-section. The velocity is zero at the channel boundary and maximum at or near the free surface. This experiment deals with the velocity distribution in an open channel and determination of the velocity using pitot tube. Practically the energy equations require to determine velocity using pitot tube (figure 1).

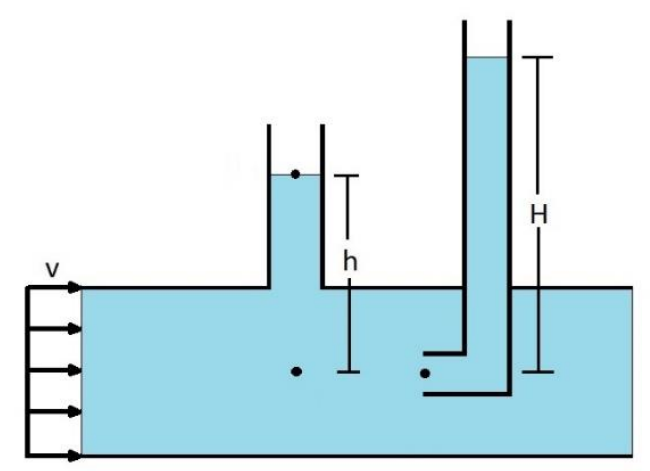

Fig 1. Velocity measurement with pitot tube

\section{Objectives}

1. To understand the function of pitot tube.

2. To understand the velocity distribution of open channel.

3. To determine the mean velocity of channel.

4. To compare the measured velocity with theoretical velocity. 
Procedure

1. Lower sluice gate until the tip is $10 \mathrm{~mm}$ above the bed.

2. Raise overshot weir at outlet until tip is $80 \mathrm{~mm}$ above the bed.

3. Move upstream Pitot to the height of the sluice gate.

4. Measure the pressures at the bed $\left(H_{B}\right)$ and the sluice gate height $\left(H_{A}\right)$ using the corresponding pitots.

5. Measure the depth (y).

6. Use a stopwatch to find the time that it takes to have 20 liters of water in the outlet tank (t).

7. Change the discharge and carry out the first three steps for two more discharges.

8. Carry out the above-mentioned steps when the sluice gate is open for $20 \mathrm{~mm}$.

\section{Theory}

When water enters a channel the velocity distribution across the channel section will vary with distance due to the presence of boundary roughness as shown in Fig. 2:

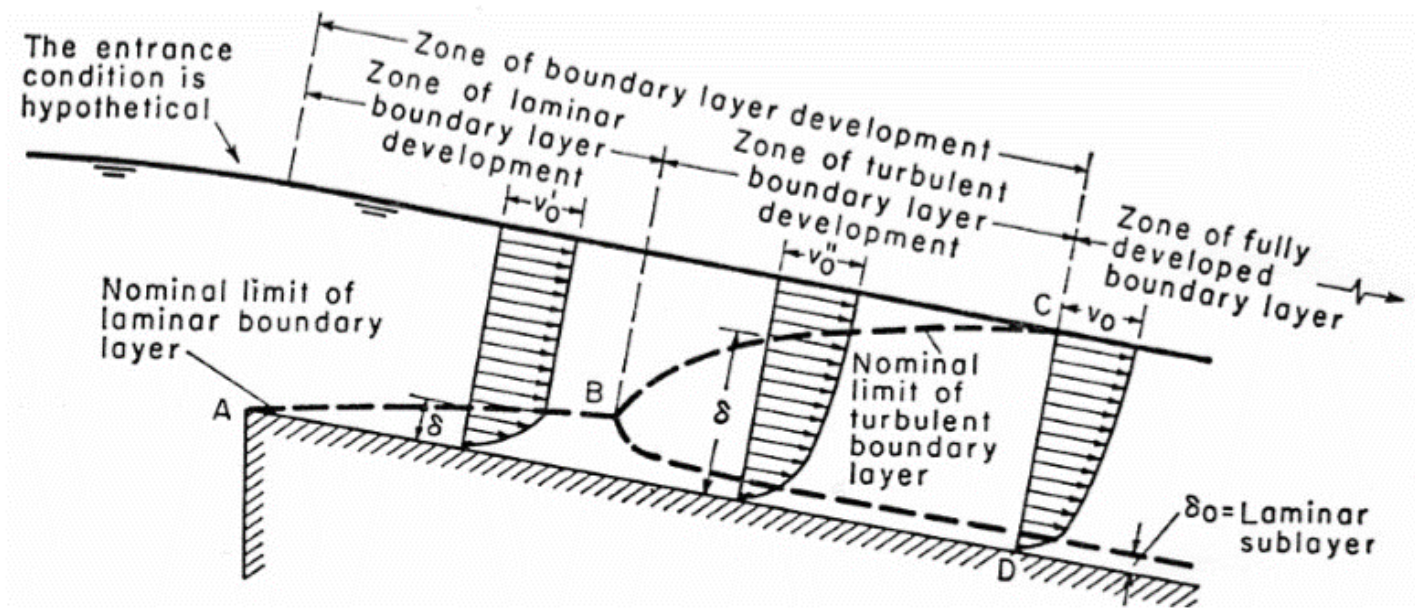

Fig 2. Development of boundary layer

The effect on the velocity distribution due to boundary roughness is indicated by the line $\mathrm{ABC}$. Outside the surface represented by $\mathrm{ABC}$, the velocity distribution is practically uniform. Near the channel surface and within the region $\mathrm{ABC}$, velocity varies according to distance from channel surface. The region inside $\mathrm{ABC}$ is known as boundary layer. At the beginning of the flow in the channel, the flow is entirely laminar, and a laminar boundary layer is developed along the channel surface, as shown by the curve $\mathrm{AB}$. The velocity distribution in this layer is approximately parabolic. As water travels further along the channel, the flow in the boundary layer will eventually change to turbulent (at point B). Downstream from B a turbulent boundary layer is developed, as shown by the curve BC. The velocity distribution in this layer is approximately logarithmic. The 
turbulent boundary layer intersects the free water surface at a distance where the flow is assumed to be fully developed.

Even in a turbulent boundary layer, there is a very thin layer near the boundary in which the flow is laminar and is known as the laminar sublayer. The thickness of this layer is given by:

$$
\delta_{0}=\frac{11.6 v}{v_{f}}
$$

Where, $v_{f}$ is the shear or friction velocity, given by:

$$
v_{f}=\sqrt{g R S}
$$

$R$ is the hydraulic radius, $S$ is the slope of the energy line (taken to be equal to the slope of the channel bottom) and $v$ is the kinematic viscosity of water.

The surface of a channel is composed of irregular peaks and valleys. The effective height of the irregularities is called the roughness height $\mathrm{k}$. If the roughness height is less than the thickness of the laminar sublayer, the surface irregularities will be so small that all roughness elements will be submerged in the laminar sublayer and have no effect upon the flow outside the layer. Then the channel is said to be hydraulically smooth. For hydraulically smooth channel.

$$
0 \leq \frac{k v_{f}}{v} \leq 5 ; \text { if } k<\delta_{0}
$$

However, if the roughness height $\mathrm{k}$ is greater than the thickness of the laminar sublayer, the roughness elements extend their effects beyond the laminar sublayer and the channel is said to be hydraulically rough. For hydraulically rough channel.

$$
\frac{k v_{f}}{v} \geq 70 ; \text { if } k>\delta_{0}
$$

There exists a transition zone in which the channel is neither smooth nor rough. For this zone:

$$
5<\frac{k v_{f}}{v}<70
$$

The flow of water in open channel is turbulent and the bed is normally rough. On the basis of Prandtl-von Karman logarithmic velocity distribution law, the velocity distribution in an open channel having hydraulically rough surface is given by:

$$
V=5.75 v_{f} \log \frac{30 y}{k}
$$

Where, $\mathrm{v}$ is the velocity at any point at a vertical distance of $\mathrm{y}$ from the channel bottom. 
The velocity varies in the vertical direction as well as in the lateral direction due to boundary friction. Cross-sectional mean velocity represents the average velocity over the cross-section. Using the velocity distribution given by above equation, the cross-sectional mean velocity $\mathrm{V}$ is given by

$$
V=v_{f}\left(6.25+5.75 \log \frac{R}{k}\right)
$$

\section{Velocity measurement}

The velocity in point A can be calculated using the Pitot tube and manometer in point A and B (figure 3). From Bernoulli equation the total head in points A and B is as follows:

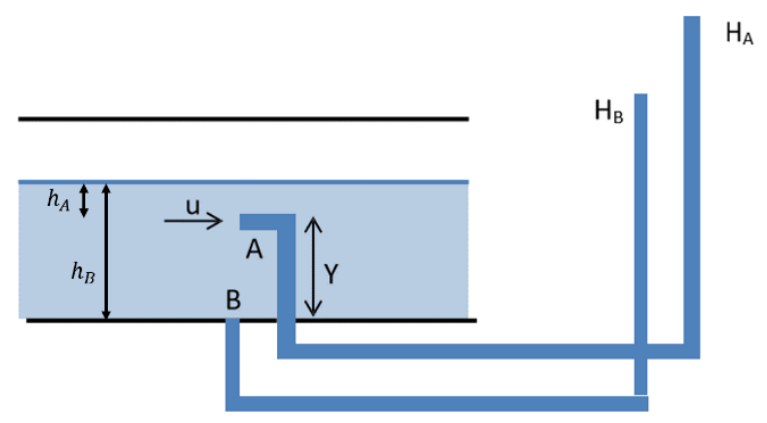

Fig 3. Experimental data measurement

$$
\begin{gathered}
H_{A}=h_{A}+y+\frac{u^{2}}{2 g} \\
\Rightarrow h_{A}=H_{A}-y-\frac{u^{2}}{2 g} \\
H_{B}=h_{B}+0+0 \Rightarrow h_{B}=H_{B}
\end{gathered}
$$

The static head of points A and B are related based on the following equation (figure 3):

$$
h_{B}=h_{A}+y
$$

Finally, substituting the value of the static head $h_{A}$ and $h_{B}$, we can easily calculate the velocity in point A:

$$
\begin{aligned}
& H_{B}=H_{A}-y-\frac{u^{2}}{2 g}+y \\
& \Rightarrow u=\sqrt{2 g\left(H_{A}-H_{B}\right)}
\end{aligned}
$$




\section{Raw Data}

For upstream section fill the following tables.

Table 1 - Sluice gate tip $10 \mathrm{~mm}$ above the bed

\begin{tabular}{|l|c|c|c|c|}
\hline & $t(\mathrm{sec})$ & $y(\mathrm{~mm})$ & $H_{A}(\mathrm{~mm})$ & $H_{B}(\mathrm{~mm})$ \\
\hline 1 & & & & \\
\hline 2 & & & & \\
\cline { 1 - 1 } & & & & \\
\cline { 1 - 1 } & & & & \\
\hline
\end{tabular}

Table 2 - Sluice gate tip $20 \mathrm{~mm}$ above the bed

\begin{tabular}{|c|c|c|c|c|}
\hline & $t(\mathrm{sec})$ & $y(\mathrm{~mm})$ & $H_{A}(\mathrm{~mm})$ & $H_{B}(\mathrm{~mm})$ \\
\hline 1 & & & & \\
\hline 2 & & & & \\
\hline 3 & & & & \\
\hline
\end{tabular}

Analyzed Data

Using all the data collected in the previous step, fill in the following tables:

Table 3 - Sluice gate tip $10 \mathrm{~mm}$ above the bed

\begin{tabular}{|l|l|l|c|l|c|c|c|}
\hline & $t(\mathrm{sec})$ & $\begin{array}{c}\text { Volume } \\
\left(\mathrm{mm}^{3}\right)\end{array}$ & $\begin{array}{c}Q_{a} \\
\left(\mathrm{~mm}^{3} / \mathrm{s}\right)\end{array}$ & $y(\mathrm{~mm})$ & $\begin{array}{c}H_{A}-H_{B} \\
(\mathrm{~mm})\end{array}$ & $u$ & $\begin{array}{c}Q_{t} \\
\left(\mathrm{~mm}^{3} / \mathrm{s}\right)\end{array}$ \\
\hline 1 & & & & & & & \\
\hline 2 & & & & & & & \\
\hline 3 & & & & & & & \\
\hline
\end{tabular}


Table 4 - Sluice gate tip $20 \mathrm{~mm}$ above the bed

\begin{tabular}{|l|l|l|l|l|l|l|l|}
\hline & $t(\mathrm{sec})$ & $\begin{array}{c}\text { Volume } \\
\left(\mathrm{mm}^{3}\right)\end{array}$ & $\begin{array}{c}Q_{a} \\
\left(\mathrm{~mm}^{3} / \mathrm{s}\right)\end{array}$ & $y(\mathrm{~mm})$ & $\begin{array}{c}H_{A}-H_{B} \\
(\mathrm{~mm})\end{array}$ & $u$ & $\begin{array}{c}Q_{t} \\
\left(\mathrm{~mm}^{3} / \mathrm{s}\right)\end{array}$ \\
\hline 1 & & & & & & & \\
\hline 2 & & & & & & & \\
\hline 3 & & & & & & & \\
\hline
\end{tabular}

\section{Lab Questions}

1. What is the main assumption when the value of discharge is calculated using Bernoulli's equation?

2. What do you mean by hydraulically smooth and rough channels? What is the criterion used to determine whether a surface is hydraulically smooth or rough?

3. Explain why the velocity distribution over a channel section is not uniform.

4. Plot the theoretical discharge on the $\mathrm{X}$-axis and the experimental discharge on the $\mathrm{Y}$-axis. Do these two values agree with each other? If not, what are the main reasons?

5. Calculate the percentage of error in your velocity measurement?

\section{Report format}

Students are expected to submit the lab report in the following format. Report will be evaluated in $100 \%$. The distribution of total marks is shown in bracket in the table below. Please submit a soft copy (pdf) in the webcourses assignment section. You can send any questions regarding Lab by webcourses inbox. Please prepare a pdf file in the following format and mention the course number in the subject line.

“CWR4202CLab-LastName-FirstName-Labno.pdf” (For example, CWR4202CLab-Sarker Shiblu-Lab02.pdf)

\begin{tabular}{|l|l|l|}
\hline & Cover Page & $\begin{array}{l}\text { Please provide the course number, course name, experiment name, } \\
\text { your name and submission date. }\end{array}$ \\
\hline 1 & Introduction $(5 \%)$ & $\begin{array}{l}\text { Not more than } 200 \text { words. It may include the background and scope } \\
\text { of the experiment. }\end{array}$ \\
\hline
\end{tabular}




\begin{tabular}{|l|l|l|}
\hline 2 & Objective (5\%) & Please formulate the main objective (goal, aim) of the experiment. \\
\hline 3 & Procedure (5\%) & $\begin{array}{l}\text { Please provide step by step procedure how the experiment can be } \\
\text { done. }\end{array}$ \\
\hline 4 & $\begin{array}{l}\text { Experimental data } \\
(10 \%)\end{array}$ & $\begin{array}{l}\text { Please present the raw data in tabular format mentioning the proper } \\
\text { unit and symbol. }\end{array}$ \\
\hline 5 & $\begin{array}{l}\text { Sample calculation } \\
(20 \%)\end{array}$ & $\begin{array}{l}\text { In this section, please present the calculation of different parameters } \\
\text { from the experimental data along with mathematical equations } \\
\text { provided in the manual. }\end{array}$ \\
\hline 6 & $\begin{array}{l}\text { Results (15\%) } \\
\text { Please present your results in tabular format. If it is required to } \\
\text { present it by graph, chart etc., please put those in this section. }\end{array}$ \\
\hline 7 & $\begin{array}{l}\text { Answer to the lab } \\
\text { questions (20\%) }\end{array}$ & $\begin{array}{l}\text { Please provide the answers to the lab questions. Please try to answer } \\
\text { what is asked for. }\end{array}$ \\
\hline 8 & Discussion (15\%) & $\begin{array}{l}\text { In this part, please discuss your results. If any kind of error, unusual } \\
\text { results etc. are found, please discuss it in this section. Try to be } \\
\text { precise and write to the point which is asked for. Also write the } \\
\text { practical value of the experiment. }\end{array}$ \\
\hline 9 & Conclusions (5\%) & \begin{tabular}{l} 
Please write a short conclusion (not more than 50 words). \\
\hline
\end{tabular}
\end{tabular}




\section{Chapter 3: Study on Hydraulic Jump}

\section{Purpose}

The main purpose of this experiment is to study hydraulic jump and to use momentum equation to describe this phenomenon.

\section{Equipment}

1. S16 Armfield Hydraulic Flow Demonstrator

2. Stopwatch

\section{General}

In an open channel when a supercritical flow is made to change abruptly to subcritical flow, the result is usually an abrupt rise of the water surface. This feature is known as the hydraulic jump. It results when there is a conflict between upstream and downstream controls which influence the same reach of the channel. For example, if the upstream control causes supercritical flow and downstream control dictates subcritical flow, then this conflict can be resolved by a hydraulic jump, which passes the flow from one flow regime to other.

This experiment deals with observation of hydraulic jump in a horizontal rectangular channel and development of different relationships between height, length, efficiency and energy loss of a jump. Hydraulic jump is useful in dissipation of excess energy in flows over dams, weirs, spillways and other hydraulic structures to prevent scouring downstream, maintaining high water levels in channels for irrigation and other water distribution purposes, increasing discharge of a sluice gate and thus increasing the effective head across the gate, mixing chemicals for water purification or wastewater treatment, increasing aeration of flows and dichlorination of waste water, identification of special flow conditions, etc. For details please see (Sarker, 2021a).

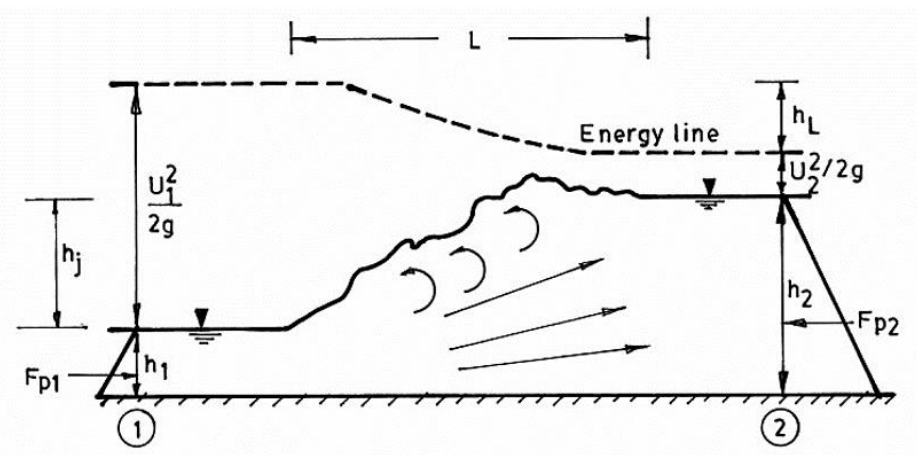

Fig 1. Hydraulic Jump in a horizontal rectangular channel 


\section{Objectives}

1. To determine the type of the jump according to USBR classification.

2. To measure the initial depth $\left(y_{1}\right)$, sequent depth $\left(y_{2}\right)$, length $(L)$ and height $\left(h_{j}\right)$ of the jump and compare them with the theoretical values.

3. To determine the total energy loss, kinetic energy loss and efficiency of the jump and compare them with the theoretical values.

4. To develop the theoretical characteristic curves of the hydraulic jump.

Procedure

1. Open the upstream gate for $10 \mathrm{~mm}$.

2. With a constant value of downstream height of the gate, change the discharge to get a stable hydraulic jump in the middle of the channel.

3. Measure the depth in upstream of the gate $\left(y_{0}\right)$, before the jump $\left(y_{1}\right)$ and after the jump $\left(y_{2}\right)$, the length of the jump $(L)$ and the time $(t)$ it takes to have 20 liters of water in inlet tank.

4. Repeat the experiment for 5 different conditions (discharge and gates' opening).

\section{Theory}

Types of hydraulic jump:

Depending on the Froude number before the jump (F1), the United States Bureau of Reclamation (USBR) classified the hydraulic jumps in horizontal rectangular channels into the following five categories:

Type 1: $F_{1}=1 \sim 1.7$ Undular jump

Type 2: $F_{1}=1.7 \sim 2.5$ Weak jump

Type 3: $F_{1}=2.5 \sim 4.5$ Oscillating jump

Type 4: $F_{1}=4.5 \sim 9.0$ Steady jump

Type 5: $F_{1}>9.0$ Strong jump

Initial and sequent depths:

The depth of flow before the jump is known as the initial depth $\left(y_{1}\right)$ and the depth after the jump is known as the sequent depth $\left(y_{2}\right)$. Consider a hydraulic jump occurring in a horizontal rectangular channel (Fig. 1). Since the jump takes place in a short reach of the channel, $F_{f} \approx 0$ and since the channel is prismatic, we can assume that $\beta_{1}=\beta_{2}=1$. The hydrostatic forces $F_{p 1}$ and $F_{p 2}$ may be expressed as

$$
F_{p 1}=\gamma \overline{z_{1}} A_{1} \text { and } F_{p 2}=\gamma \overline{z_{2}} A_{2}
$$


Where, $\overline{z_{1}}$ and $\overline{z_{2}}$ are the vertical distances of the centroids of the respective water areas $A_{1}$ and $A_{2}$ from the free surface. Now applying momentum equation (Reza et al., 2014; Sarker, 2021e, 2021a) between sections 1 and 2, we obtain

$$
\frac{Q^{2}}{g A_{1}}+\overline{z_{1}} A_{1}=\frac{Q^{2}}{g A_{2}}+\overline{z_{2}} A_{2}
$$

Since for a rectangular channel $Q=A_{1} V_{1}=A_{2} V_{2} ; A_{1}=B y_{1}$ and $A_{2}=B y_{2} \overline{z_{1}}=y_{1} / 2$ and $\overline{z_{2}}=$ $y_{2} / 2$ above equation gives

$$
\frac{Q^{2}}{g B^{2}}\left(\frac{1}{y_{1}}-\frac{1}{y_{2}}\right)=\frac{1}{2}\left(y_{2}^{2}-y_{1}^{2}\right)
$$

Using $Q=B y_{1} V_{1}=B y_{2} V_{2}$ above equation may be recast as

$$
\frac{V_{1}^{2}}{g y_{1}}=F_{1}^{2}=\frac{1}{2} \frac{y_{2}}{y_{1}}\left(\frac{y_{2}}{y_{1}}+1\right)
$$

Which may be solved to yield

$$
\frac{y_{2}}{y_{1}}=\frac{1}{2}\left(\sqrt{1+8 F_{1}^{2}}-1\right)
$$

Where, $\frac{y_{2}}{y_{1}}$ is known as the ratio between the sequent and the initial depths.

Length of the jump (L)

The length of a hydraulic jump is the horizontal distance from the front face of the jump to a point immediately downstream from the roller. This length cannot be determined by theory. Silvester (1964) demonstrated that for free hydraulic jumps in horizontal rectangular channels

$$
\frac{L}{y_{1}}=9.75\left(F_{1}-1\right)^{1.01}
$$

Energy loss in the jump

The total loss of energy in the jump is equal to the difference in specific energies before and after the jump. It can be shown that the total energy loss involved in a hydraulic jump in a horizontal rectangular channel is given by

$$
\Delta E=E_{1}-E_{2}=\frac{\left(y_{2}-y_{1}\right)^{3}}{4 y_{1} y_{2}}
$$

Where, $E_{1}$ is the specific energy before the jump and $E_{2}$ is the specific energy after the jump. The kinetic energy loss in the jump is given by the difference in velocity head before and after the jump. Thus 


$$
\Delta E_{K . E .}=\frac{1}{2 g}\left(V_{1}^{2}-V_{2}^{2}\right)
$$

Where, $V_{1}$ is the velocity before the jump and $V_{2}$ is the velocity after the jump.

Efficiency of the jump

The ratio of the specific energy after the jump to that before the jump $\left(E_{2} / E_{1}\right)$ is known as the efficiency of the jump. It can be shown that the efficiency of the jump is given by

$$
\frac{E_{2}}{E_{1}}=\frac{\left(1+8 F_{1}^{2}\right)^{3 / 2}-4 F_{1}^{2}+1}{8 F_{1}^{2}\left(2+F_{1}^{2}\right)}
$$

Height of the jump

The difference between the depths after and before the jump is known as the height of the jump. It is given by $h_{j}=y_{2}-y_{1}$

The ratio of the height of jump to the specific energy before jump is known as the relative height of the jump and is given by

$$
\frac{h_{j}}{E_{1}}=\frac{\left(1+8 F_{1}^{2}\right)^{1 / 2}-3}{2+F_{1}^{2}}
$$

Typical shapes of graphs

Characteristic graphs of hydraulic jumps are a combination of four graphs shown in Fig. 2.

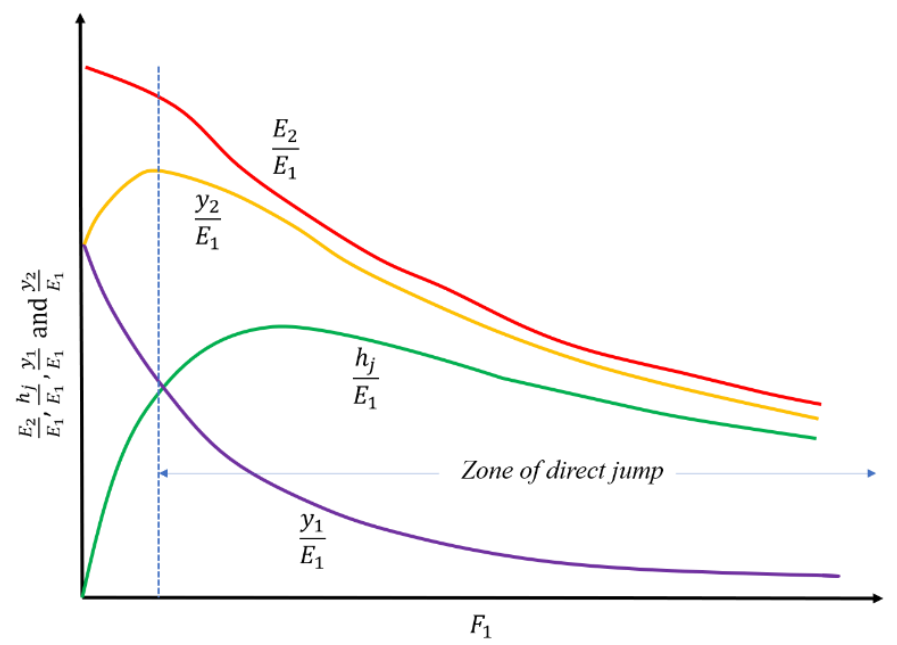

Fig 2. Characteristics curves of hydraulic jumps in horizontal rectangular channels 


\section{Raw Data}

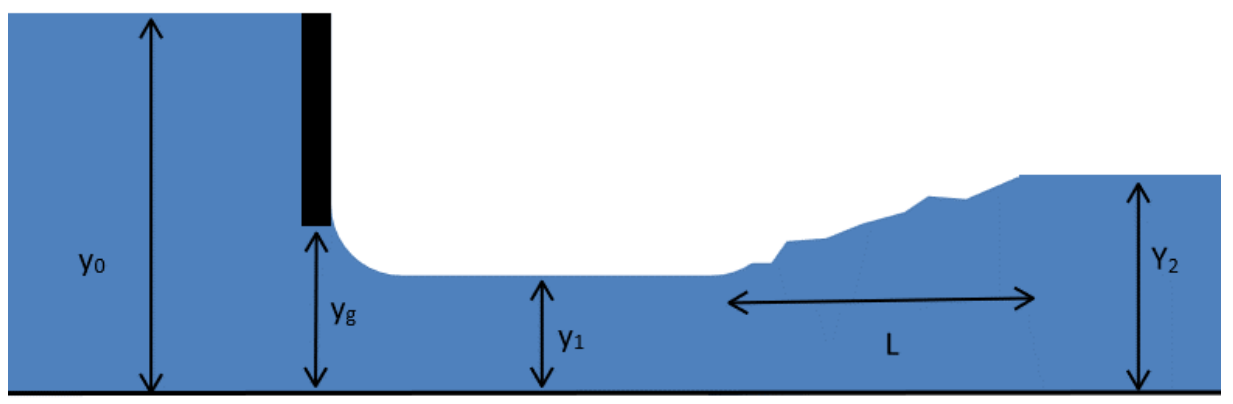

Fig 3. Experimental data measurement

Record the values of $y_{1}, y_{2}, h_{j}, L$ and $t$ in the following table.

Table 1

\begin{tabular}{|c|c|c|c|c|c|}
\hline & $y_{1}(\mathrm{~mm})$ & $y_{2}(\mathrm{~mm})$ & $h_{j}(\mathrm{~mm})$ & $\mathrm{L}(\mathrm{mm})$ & $\mathrm{t}(\mathrm{s})$ \\
\hline 1 & & & & & \\
\hline 2 & & & & & \\
\hline 3 & & & & & \\
\hline 4 & & & & & \\
\hline 5 & & & & & \\
\hline
\end{tabular}

Analyzed Data

First, having known the time and volume, calculated the discharge and then estimate the following table: 
Table 2

\begin{tabular}{|l|c|c|c|c|c|c|c|c|}
\hline & $\begin{array}{c}\mathrm{Q} \\
(\mathrm{mm} / \mathrm{s})\end{array}$ & $\begin{array}{c}y_{1} \\
(\mathrm{~mm})\end{array}$ & $\begin{array}{c}v_{1} \\
(\mathrm{~mm} / \mathrm{s})\end{array}$ & $\begin{array}{c}E_{1} \\
(\mathrm{~mm})\end{array}$ & $\begin{array}{c}y_{2} \\
(\mathrm{~mm})\end{array}$ & $\begin{array}{c}v_{2} \\
(\mathrm{~mm} / \mathrm{s})\end{array}$ & $\begin{array}{c}E_{2} \\
(\mathrm{~mm})\end{array}$ & $\begin{array}{c}\Delta E=E_{1}-E_{2} \\
(\mathrm{~mm})\end{array}$ \\
\hline 1 & & & & & & & & \\
\hline 2 & & & & & & & & \\
\hline 3 & & & & & & & & \\
\hline 5 & & & & & & & & \\
\hline
\end{tabular}

Calculate the theoretical values (i.e., sequent depth, length, energy loss, efficiency and height) for your observed hydraulic jump in the following table:

Table 3

\begin{tabular}{|l|c|c|c|c|c|c|c|c|c|c|}
\hline & $\begin{array}{c}y_{1} \\
(\mathrm{~mm})\end{array}$ & $\begin{array}{c}v_{1}=\frac{Q}{b y_{1}} \\
(\mathrm{~mm} / \mathrm{s})\end{array}$ & $F_{1}=\frac{v_{1}}{\sqrt{g y_{1}}}$ & $\begin{array}{c}y_{2} \\
(\mathrm{~mm})\end{array}$ & $\begin{array}{c}\mathrm{L} \\
(\mathrm{mm})\end{array}$ & $\frac{y_{1}}{E_{1}}$ & $\frac{y_{2}}{E_{1}}$ & $\frac{h_{j}}{E_{1}}$ & $\frac{E_{2}}{E_{1}}$ & $\Delta E$ \\
\hline 1 & & & & & & & & & \\
\hline 2 & & & & & & & & & \\
\hline 4 & & & & & & & & & \\
\hline 5 & & & & & & & & & & \\
\hline
\end{tabular}

Note. The highlighted columns are values that are measured. So, you have to use them to complete the rest of the table. 


\section{Lab Questions}

1. What is the type of your hydraulic jump according to USBR classification?

2. We assume that the loss in two sides of the gate in negligible when we use energy equation. Does this assumption seem realistic?

3. Do the calculated values for $y_{2}$, agree with the measured values? What can be the reason for the differences?

4. Plot the curve of $L$ versus $y_{2}-y_{1}$. Using this curve, find the value of $\alpha$ (slope of the straight line). The value of $y_{2}-y_{1}$ should be in horizontal axes.

5. Plot $\frac{E_{2}}{E_{1}}, \frac{h_{j}}{E_{1}}, \frac{y_{1}}{E_{1}}$ and $\frac{y_{2}}{E_{1}}$ vs $F_{1}$ to get the characteristics curves?

Note. In order to draw the curves, use "scatter with only markers" chart in excel. To find out the value of $\alpha$, you can use "add trendline" option in Excel. The slope of the curve is the value of $\alpha$.

\section{Report format}

Students are expected to submit the lab report in the following format. Report will be evaluated in $100 \%$. The distribution of total marks is shown in bracket in the table below. Please submit a soft copy (pdf) in the webcourse assignment section. You can send any questions regarding Lab by webcourses inbox. Please prepare a pdf file in the following format and mention the course number in the subject line.

“CWR4202CLab-LastName-FirstName-Labno.pdf" (For example, CWR4202CLab-Sarker Shiblu-Lab03.pdf)

\begin{tabular}{|l|l|l|}
\hline & Cover Page & $\begin{array}{l}\text { Please provide the course number, course name, experiment name, } \\
\text { your name and submission date. }\end{array}$ \\
\hline 1 & Introduction (5\%) & $\begin{array}{l}\text { Not more than } 200 \text { words. It may include the background and scope } \\
\text { of the experiment. }\end{array}$ \\
\hline 2 & Objective (5\%) & Please formulate the main objective (goal, aim) of the experiment. \\
\hline 3 & Procedure (5\%) & $\begin{array}{l}\text { Please provide step by step procedure how the experiment can be } \\
\text { done. }\end{array}$ \\
\hline 4 & $\begin{array}{l}\text { Experimental data } \\
(10 \%)\end{array}$ & $\begin{array}{l}\text { Please present the raw data in tabular format mentioning the proper } \\
\text { unit and symbol. }\end{array}$ \\
\hline
\end{tabular}




\begin{tabular}{|l|l|l|}
\hline 5 & $\begin{array}{l}\text { Sample calculation } \\
(20 \%)\end{array}$ & $\begin{array}{l}\text { In this section, please present the calculation of different parameters } \\
\text { from the experimental data along with mathematical equations } \\
\text { provided in the manual. }\end{array}$ \\
\hline 6 & Results (15\%) & $\begin{array}{l}\text { Please present your results in tabular format. If it is required to } \\
\text { present it by graph, chart etc., please put those in this section. }\end{array}$ \\
\hline 7 & $\begin{array}{l}\text { Answer to the lab } \\
\text { questions (20\%) }\end{array}$ & $\begin{array}{l}\text { Please provide the answers to the lab questions. Please try to answer } \\
\text { what is asked for. }\end{array}$ \\
\hline 8 & Discussion (15\%) & $\begin{array}{l}\text { In this part, please discuss your results. If any kind of error, unusual } \\
\text { results etc. are found, please discuss it in this section. Try to be } \\
\text { precise and write to the point which is asked for. Also write the } \\
\text { practical value of the experiment. }\end{array}$ \\
\hline 9 & Conclusions (5\%) & \begin{tabular}{l} 
Please write a short conclusion (not more than 50 words). \\
\hline
\end{tabular}
\end{tabular}




\section{Chapter 4: Flow over Hydraulic Structures}

Purpose

The purpose of this experiment is to determine the theoretical discharge of the weir (1. Sharp crested weir, 2. Broad crested weir) and measure the actual discharge and hence to find out the coefficient of discharge.

Equipment

1. S16 Armfield Hydraulic Flow Demonstrator

2. Stopwatch

3. Flow meter

4. Sharp crested weir

5. Broad crested weir

\section{General}

A weir is an overflow structure built across an open channel for the purpose of measuring the flow. Weirs are commonly used to measure flow of water, but their use in measurement of other liquids is increasing.

Classified with reference to the shape of the opening through which the liquid flows, weirs may be rectangular, triangular, trapezoidal, circular, parabolic or of any other regular form. The first three forms are most commonly used for measurement of water. Classified with reference to the form of crest (the edge or the top surface with which liquid comes in contact) weirs may be sharpcrested or broad-crested. The sharp-crested rectangular weir has a sharp upstream edge so formed that the liquid in passing touches only a line.

The overfalling stream is termed as 'nappe'. The nappe of a sharp crested weir as shown in fig is contracted at its underside by the action of the vertical components of the velocity just upstream from the weir. This is called crest contraction. If the sides of the opening also have sharp upstream edge so that the nappe is contracted in width, the weir is said to have end contractions and is usually called a contracted weir.

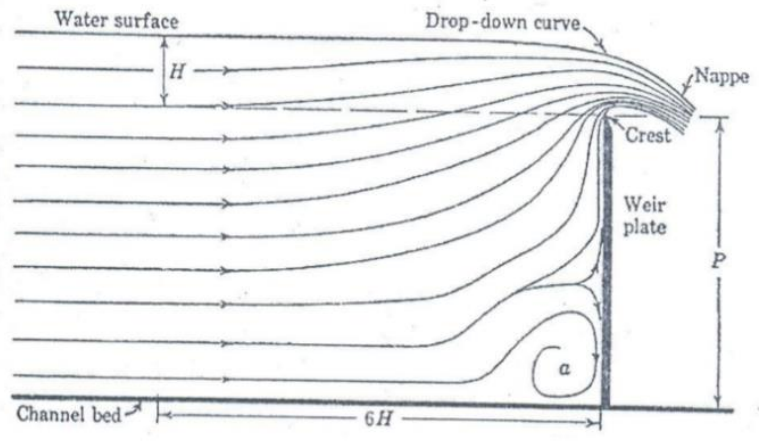

Fig 1. Path lines of flow over rectangular sharp crested weir 
A broad-crested weir is an overflow structure with a truly level and horizontal crest. It is widely used in irrigation canals for the purpose of flow measurement as it is rugged and can stand up well under field conditions. But practically some problems arise with the weir, as there exists a dead water zone at the upstream of the weir and the head loss is more comparable to other devices. By virtue of being a critical depth meter, the broad crested weir has the advantage that it operates effectively with higher downstream water levels than a sharp crested weir. This experiment deals with measurement of discharge using the broad crested weir and also calibration of the weir.

\section{Practical application}

Shallow rivers are often made navigable by building, dams across the river at certain sections over which the water may flow. During a drought little or no water will flow past the dam, but after heavy rains the water flows over the dam, thus converting it into a weir. Also flow through canal is measured by weirs. Hydraulic structure formula also useful to understand the effect of structure in dynamic river (see Khan et al., 2014)

Experimental setup

1. Open all the gates and measure the height $(\mathrm{P})$ and width $(\mathrm{B})$ of the weir. Position the weir plate at end side of the approach channel, in a vertical plane, with sharp edge on the upstream side.

2. Allow water to the channel so that water flows over the weir and wait until water surface comes to a steady condition.

3. Ventilate the nappe.

4. Check again whether the nappe is ventilated or not. If not, ventilate it.

5. Carefully take the gauge reading (upstream water level over the weir). The water surface may be slightly fluctuating.

6. Take the time to accumulate 20 liters in the tank and calculate actual discharge and hence find the coefficient of discharge.

Theory

The relationship between discharge and head over the weir can be developed by making the following assumptions as to the flow behavior:

1. Upstream of the weir, the flow is uniform, and the pressure varies with depth according to the hydrostatic equation $P=\gamma h$

2. The free surface remains horizontal as far as the plane of the weir, and all particles passing over the weir move horizontally. (In fact, the free surface drops as it approaches the weir).

3. The pressure throughout the sheet of liquid or nappe, which passes over the crest of the weir, is atmospheric.

4. The effects of viscosity and surface tension are negligible.

5. The upstream approach velocity head is neglected. 


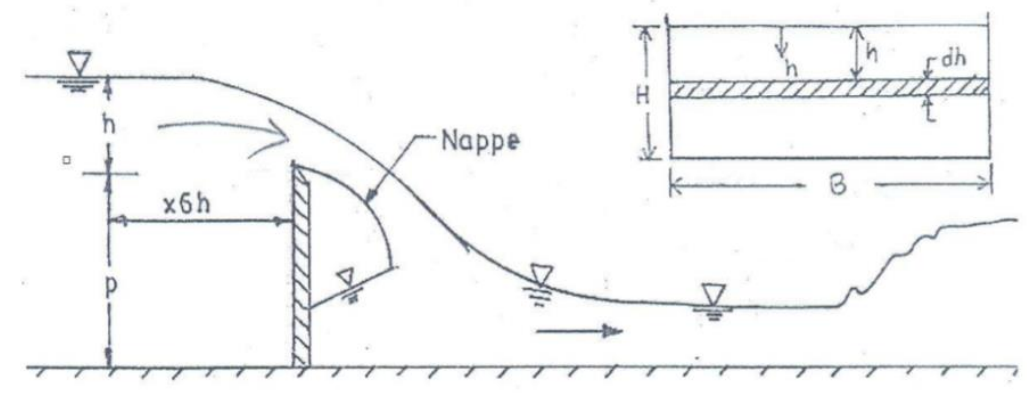

Fig 2. Flow Over a Sharp-Crested weir

Now consider the sharp-crested weir in the figure. Let $\mathrm{H}$ be the working head and $\mathrm{B}$ is the width of the weir. Let us consider a small horizontal string of thickness dh under a head $h$. Therefore, the theoretical discharge through the strip

$$
d Q_{1}=\text { areaofthestrip } * \text { velocity }=(B d h) * \sqrt{2 g h}
$$

Integrating between the limits 0 and $\mathrm{H}$, the total theoretical discharge over the weir is given by

$$
Q_{t}=\frac{2}{3} \sqrt{2 g} * B * H^{(3 / 2)}
$$

Let $Q_{a}$ be the actual discharge. Then the co-efficient of discharge, $C_{d}$, is given by

$$
C_{d}=Q_{a} / Q_{t}
$$

The broad-crested weir has a definite crest length in the direction of flow. In order to maintain a hydrostatic pressure distribution above the weir crest, i.e., to maintain the streamlines straight and parallel, the length of the weir is designed such that $0.07 \leq H_{1} / L \leq 0.50$ where $H_{1}$ is the head above the crest and $L$ is the length of the weir (Fig. 3). Under this condition, critical flow occurs over the weir and the weir provides an excellent means of measuring discharge in open channels based on the principle of critical flow. The upstream corner of the weir is rounded in such a manner that flow separation does not occur. 


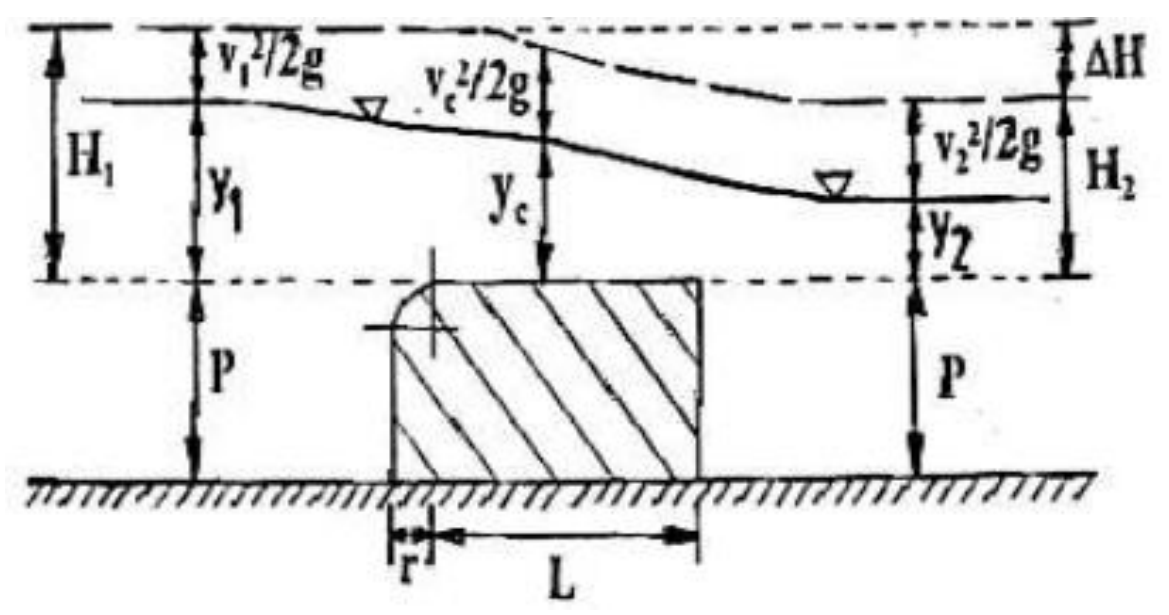

Fig 3. Flow Over a Broad-Crested weir

Consider a rectangular broad crested weir shown in figure 3 Based on the principle of critical flow $(F r=1)$, the theoretical discharge $Q_{t}$ over the weir is given by

$$
Q_{t}=\sqrt{g} * B * y_{c}^{(3 / 2)}
$$

Where, $\mathrm{B}$ is the width of the weir, $y_{c}$ is the critical depth and $\mathrm{g}$ is the acceleration due to the gravity. But the usual difficulty to use this equation for computing discharge lies in locating the critical flow section and measuring the critical depth accurately. This difficulty is, however, overcome by measuring the depth of flow upstream of the weir where the flow is not affected by the presence of the weir. With reference to Fig. 3, neglecting the frictional losses and applying the energy equation between the upstream section and the critical flow section, we obtain

$$
H_{1}=y_{c}+\frac{v_{c}^{2}}{2 g}
$$

Where, $V_{c}$ is the critical velocity. Since at the critical state of flow, the velocity head is equal to one-half of the hydraulic depth $(D)$ and for a rectangular channel $D=y$, the above equation gives

$$
H_{1}=y_{c}+\frac{v_{c}^{2}}{2 g}=y_{c}+\frac{D_{c}}{2}=y_{c}+\frac{y_{c}}{2}=\frac{3}{2} y_{c}
$$

so that

$$
y_{c}=\frac{2}{3} H_{1}
$$

and the theoretical discharge $Q_{t}$ becomes

$$
Q_{t}=\left(\frac{2}{3}\right)^{3 / 2} \sqrt{g} * B * H_{1}^{(3 / 2)}
$$


Let $Q_{a}$ be the actual discharge. Then the co-efficient of discharge, $C_{d}$, is given by

$$
C_{d}=Q_{a} / Q_{t}
$$

\section{Raw Data}

(1) Sharp crested weir

Width of the weir, $\mathrm{B}=\mathrm{mm}$;

Height of the weir, $\mathrm{P}=\mathrm{mm}$.

\begin{tabular}{|l|l|l|}
\hline & Time, $\mathrm{t}(\mathrm{s})$ & Head, $\mathrm{H}(\mathrm{mm})$ \\
\hline 1 & & \\
\hline 2 & & \\
\hline 3 & & \\
\hline 4 & & \\
\hline 5 & & \\
\hline
\end{tabular}

(2) Broad crested weir

Width of the weir, $\mathrm{B}=\mathrm{mm}$

Height of the weir, $\mathrm{P}=\mathrm{mm}$.

\begin{tabular}{|l|l|l|}
\hline & Time, $\mathrm{t}(\mathrm{s})$ & Head, $\mathrm{H}(\mathrm{mm})$ \\
\hline 1 & & \\
\hline 2 & & \\
\hline 3 & & \\
\hline 4 & & \\
\hline 5 & & \\
\hline
\end{tabular}


Analyzed Data

(1) Sharp crested weir

\begin{tabular}{|l|l|l|l|l|l|}
\hline & Volume (L) & Time (s) & Discharge $\left(Q_{a}\right)$ & Head (mm) & Discharge $Q_{t}$ \\
\hline 1 & & & & & \\
\hline 2 & & & & & \\
\hline 3 & & & & & \\
\hline 4 & & & & & \\
\hline 5 & & & & & \\
\hline
\end{tabular}

(2) Broad crested weir

\begin{tabular}{|l|l|l|l|l|l|}
\hline & Volume (L) & Time (s) & Discharge $\left(Q_{a}\right)$ & Head (mm) & Discharge $Q_{t}$ \\
\hline 1 & & & & & \\
\hline 2 & & & & & \\
\hline 3 & & & & & \\
\hline 4 & & & & & \\
\hline 5 & & & & & \\
\hline
\end{tabular}

\section{Lab Questions}

1. What are the assumptions made in deriving this equation?

2. Discuss the observation of the nappe.

3. Plot the $Q_{a}$ vs $Q_{t}$ and determine the value of $C_{d}$ for sharp crested weir.

4. What is the advantage, disadvantage and use of a broad-crested weir?

5. Plot the $Q_{a}$ vs $Q_{t}$ and determine the value of $C_{d}$ for the broad crested weir.

\section{Report format}

Students are expected to submit the lab report in the following format. Report will be evaluated in $100 \%$. The distribution of total marks is shown in bracket in the table below. Please submit a soft copy (pdf) in the webcourse assignment section. You can send any questions regarding Lab by webcourses inbox. Please prepare a pdf file in the following format and mention the course number in the subject line. 
“CWR4202CLab-LastName-FirstName-Labno.pdf” (For example, CWR4202CLab-Sarker Shiblu-Lab04.pdf)

\begin{tabular}{|c|c|c|}
\hline & Cover Page & $\begin{array}{l}\text { Please provide the course number, course name, experiment name, } \\
\text { your name and submission date. }\end{array}$ \\
\hline 1 & Introduction $(5 \%)$ & $\begin{array}{l}\text { Not more than } 200 \text { words. It may include the background and scope } \\
\text { of the experiment. }\end{array}$ \\
\hline 2 & Objective (5\%) & Please formulate the main objective (goal, aim) of the experiment. \\
\hline 3 & Procedure $(5 \%)$ & $\begin{array}{l}\text { Please provide step by step procedure how the experiment can be } \\
\text { done. }\end{array}$ \\
\hline 4 & $\begin{array}{l}\text { Experimental data } \\
(10 \%)\end{array}$ & $\begin{array}{l}\text { Please present the raw data in tabular format mentioning the proper } \\
\text { unit and symbol. }\end{array}$ \\
\hline 5 & $\begin{array}{l}\text { Sample calculation } \\
(20 \%)\end{array}$ & $\begin{array}{l}\text { In this section, please present the calculation of different parameters } \\
\text { from the experimental data along with mathematical equations } \\
\text { provided in the manual. }\end{array}$ \\
\hline 6 & Results (15\%) & $\begin{array}{l}\text { Please present your results in tabular format. If it is required to } \\
\text { present it by graph, chart etc., please put those in this section. }\end{array}$ \\
\hline 7 & $\begin{array}{l}\text { Answer to the lab } \\
\text { questions }(20 \%)\end{array}$ & $\begin{array}{l}\text { Please provide the answers to the lab questions. Please try to answer } \\
\text { what is asked for. }\end{array}$ \\
\hline 8 & Discussion $(15 \%)$ & $\begin{array}{l}\text { In this part, please discuss your results. If any kind of error, unusual } \\
\text { results etc. are found, please discuss it in this section. Try to be } \\
\text { precise and write to the point which is asked for. Also write the } \\
\text { practical value of the experiment. }\end{array}$ \\
\hline 9 & Conclusions $(5 \%)$ & Please write a short conclusion (not more than 50 words). \\
\hline
\end{tabular}




\section{Chapter 5: Head losses in a pipe flow}

Purpose

The objective of this experiment is to demonstrate and calculate head losses (major loss and minor loss) in a pipe system. In this demonstration, the friction coefficients for the Darcy-Weisbach $(f)$, the Hazen-William $\left(C_{H W}\right)$, and the Manning $(n)$ equations are determined for pipes with different materials.

Equipment

1. Water storage reservoir

2. Pump

3. Flow meter

4. Pipes (opaque PVC \& clear PVC)

5. Pipe containing eight $90^{\circ}$ elbows

6. Flow network panels

7. Pressure gauge

8. Timer

\section{General}

Head loss in a pipe flow is mainly due to friction in pipes and again friction is due to roughness of pipes. It has been proved that friction is dependent not only upon the size and shape of the projection of roughness, but also upon their distribution or spacing. For details please see (Sarker, 2021a).

\section{Practical application}

Flow through a single pipeline, pipes in series and parallel and also in pipe network system, cause head loss due to friction. The head loss from source to the point of interest due to the friction along the pipe also provides the basis of pipe size (diameter) design. This experiment gives an estimate of head loss due to friction in the pipe per unit length of the pipe. Besides pipes it has wide range of use in natural and manmade network system (Reza et al., 2014; Sarker, 2021a; Sarker et al., 2018, 2019a, 2019b; Sarker \& Singh, 2017).

\section{Objectives}

1. To understand the types of flow in pipes.

2. To find the frictional loss.

3. To determine the friction coefficients for the Darcy-Weisbach $(f)$, the Hazen-William $\left(C_{H W}\right)$, and the Manning $(n)$ equations. 
Experimental setup

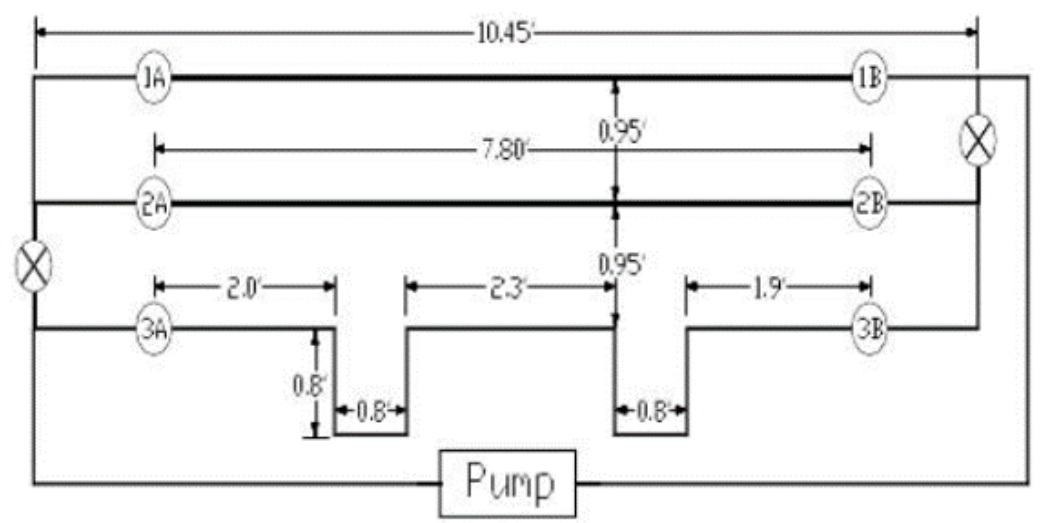

Fig 1. Experimental pipe system

\section{Procedure}

Major Loss due to Pipe Friction:

1. Set up the flow network system, as shown in the diagram, so that the water will circulate from the supply reservoir through the pipe network and back to the supply reservoir.

2. Fill the supply reservoir with water.

3. Open valves A and B for each pipe so that the flow is not restricted in the system.

4. Turn on the pump. Allow sufficient time for the air to escape from the system.

5. Close valves $\mathrm{A}(2 \mathrm{~A} \& 3 \mathrm{~A})$ and $\mathrm{B}(2 \mathrm{~B} \& 3 \mathrm{~B})$ on pipes 2 and 3 .

6. Measure the flow rate through the pipe 1 .

7. Insert the pressure gauges onto the pressure tap located near valve $1 \mathrm{~A}$ and valve $1 \mathrm{~B}$. Read the gauge pressures.

8. Vary the flow rate and measure the gauge pressures.

9. Open valves 2A and 2B. (Note: Valves A and B should always be open for at least one pipe to avoid any damage on the pump)

10. Close valves A and $\mathrm{B}$ on pipe 1.

11. Repeat steps 6 through 8 for pipe 2 .

Minor loss due to fittings:

1. Open valves $3 \mathrm{~A}$ and $3 \mathrm{~B}$ on pipe 3 containing eight $90^{\circ}$ elbows.

2. Close valves $2 \mathrm{~A}$ and $2 \mathrm{~B}$ on pipe 2.

3. Repeat steps 6 through 7 for pipe 3 .

4. Turn off the pump. 


\section{Theory}

Friction loss is the loss of energy or head that occurs in the pipe flow due to viscous effects generated by the surface of the pipe. This energy loss is dependent on the wall shear stress between the fluid and pipe surface, and the shear stress of a flow dependent on whether the flow is turbulent of laminar. For turbulent flow, the pressure drop is dependent on the roughness of the surface while in laminar flow the roughness effects of the wall are negligible. This is due to fact that for turbulent flow a thin viscous layer is formed near the pipe surface which causes loss of energy while in laminar flow this viscous layer is nonexistent. Friction loss has several causes: -Condition of flow, - Movement of fluid molecules against each other and - Movement of fluid molecules against inside surface of pipe.

If the head loss in a given length of uniform pipe is measured at different values of the velocity, it will be found that, as long as the velocity is low enough to secure laminar flow. the head loss, due to friction, will be directly proportional to the velocity. But with increasing velocity, at some point where the visual observation in a transparent tube would show that the flow changes from laminar to turbulent, there will be an abrupt increase in the rate at which the head loss varies. If the logarithms of those two variables are plotted on linear scales or if the values are plotted directly on log-log paper, it will be found that, after a certain transition region has been passed, lines will be obtained with slopes ranging from about 1.75 to 2.00. For details please see (Sarker, 2021a, 2021c).

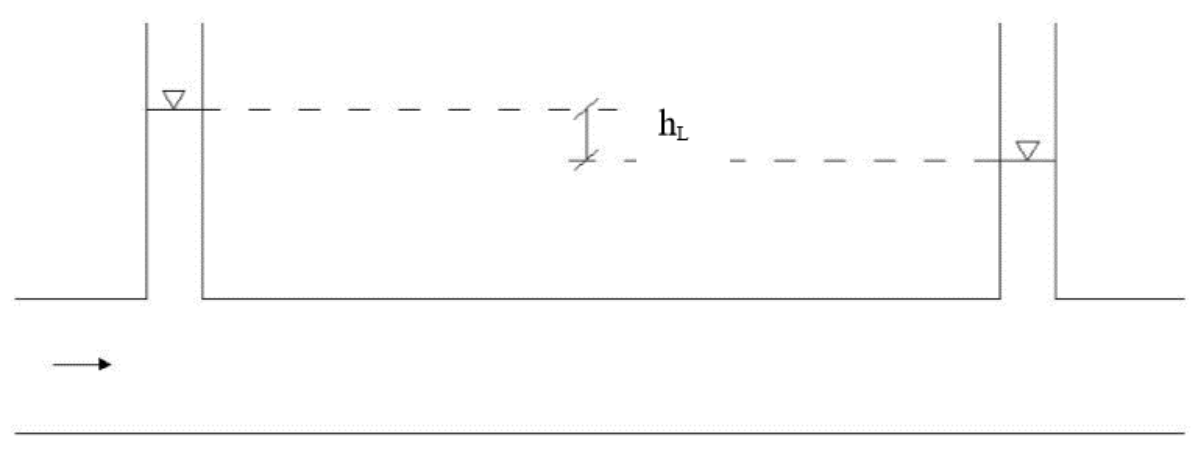

Fig 2. Head loss due to Friction in a pipe

It is thus understood that for laminar flow the drop-in energy due to friction varies as $V$, while for turbulent flow the friction varies as $V^{n}$, where $n$ ranges from about 1.75 to 2.00 . The lower value of 1.75 for turbulent flow is found for pipes with very smooth walls; as the wall roughness increases, the value of $n$ increases up to its maximum value of 2.00 .

However, velocity is not the only factor that determines whether the flow is laminar or turbulent. The criterion is Reynolds number. For a circular pipe the significant linear dimension L is usually taken as the diameter D, and thus: 


$$
R_{e}=\frac{V D}{v}
$$

For circular pipe when,

$$
\begin{aligned}
\operatorname{Re} & <2000 \text { Flow is Laminar } \\
2000 & <\operatorname{Re}<4000 \text { Flow is Transitional } \\
\operatorname{Re} & >4000 \text { Flow is Turbulent }
\end{aligned}
$$

Head loss, $h_{L}$ can be generalized as proportional with the exponential power of velocity (Sarker, 2021c), $V$ by:

$$
h_{L} \infty v^{n}
$$

where $\mathrm{n}$ is the exponent of velocity

$$
h_{L}=K v^{n}
$$

where $\mathrm{K}$ is a constant.

Early experiment on the flow of water in long, straight, uniform circular pipes indicated that head loss varied directly with velocity head and pipe length and inversely with pipe dia. Darcy Weisbach proposed the formula for the turbulent flow,

$$
h_{L}=f \frac{L}{D} \frac{v^{2}}{2 g}
$$

Where, $f=$ friction coefficient, $L=$ Length of pipe, $v=$ velocity of pipe, $D=$ Diameter of the pipe. For laminar flow head loss $\left(h_{L}\right)$ given by Hagen-Poiseuille is:

$$
h_{L}=\frac{32 \mu L v}{\rho g D^{2}}
$$

For laminar flow the striking feature of the equation is that it involves no empirical coefficient or experimental factors of any kind, except for the physical properties of fluid such as, viscosity, and density.

$$
f=\frac{64}{R_{e}} \text { (for circular pipe) }
$$

Therefore, friction factor (f) can be related empirically as:

$$
f=C R_{e}^{m}
$$


Where $\mathrm{m}$ is the exponent of Reynolds number and $C$ is a constant. From this it would appear that in laminar flow the friction is independent of the roughness of the pipe wall. Moody diagram useful to relate Darcy-Weisbach friction factor $f$, Reynolds number $R_{e}$, and surface roughness (figure 4).

Hazen-Williams also proposes the formula to calculate pipe friction factor as below:

$$
v=1.32 C_{H W} R_{h}^{0.63} S^{0.54}
$$

Where $v=$ mean velocity, $C_{H W}=$ Hazen Williams Friction Coefficient, $R_{h}=$ Hydraulic Radius, $S$ $=$ Slope of the energy grade line.

Manning's equation also applicable to calculate pipe roughness as below:

$$
v=\frac{1.49}{n} R_{h}^{2 / 3} S^{1 / 2}
$$

Where $n=$ Manning's friction coefficient.

The loss of head in a sudden contraction is not only due to the contraction itself but also due to sudden expansion which follows the contraction as shown in figure 3 . Head loss in sudden contraction:

$$
h_{C}=k_{1} v_{2}^{n}
$$

The loss of head in a sudden contraction is due to the formation of eddies at the corner as shown in figure 3 . Head loss in a sudden expansion:

$$
h_{E}=k_{2}\left(v_{2}-v_{1}\right)^{n}
$$

The loss of head in a $90^{\circ}$ elbows:

$$
h_{b}=N k_{3} \frac{v^{2}}{2 g}
$$

Where, $\mathrm{N}$ is the number of elbows and $k_{3}$ is usually 0.9 .
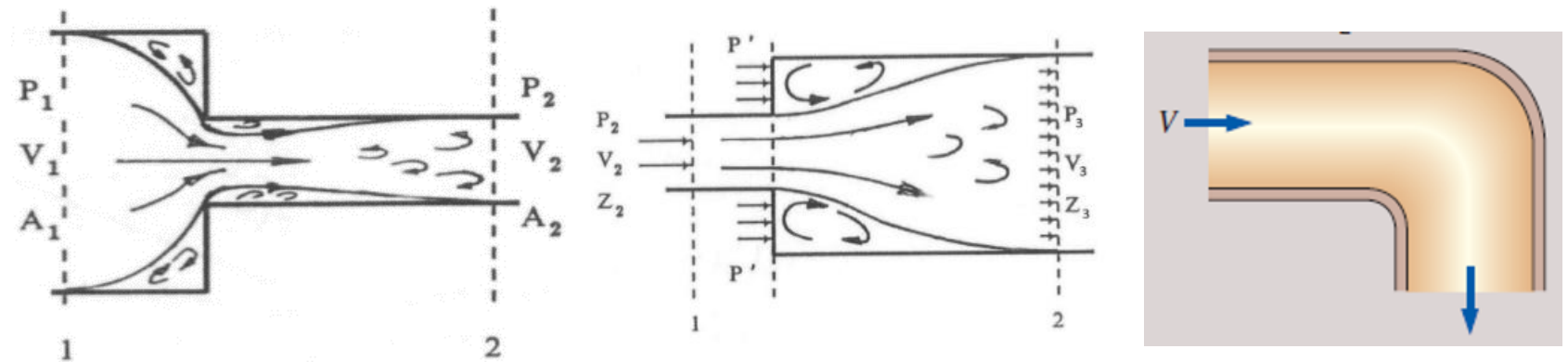

Fig 3. Theoretical formula to calculate minor losses 


\section{Moody diagram}

Moody diagram is a curve that relates the Darcy-Weisbach friction factor $f$, Reynolds number $R_{e}$, and surface roughness for fully developed flow in a circular pipe shown in Fig. 4.

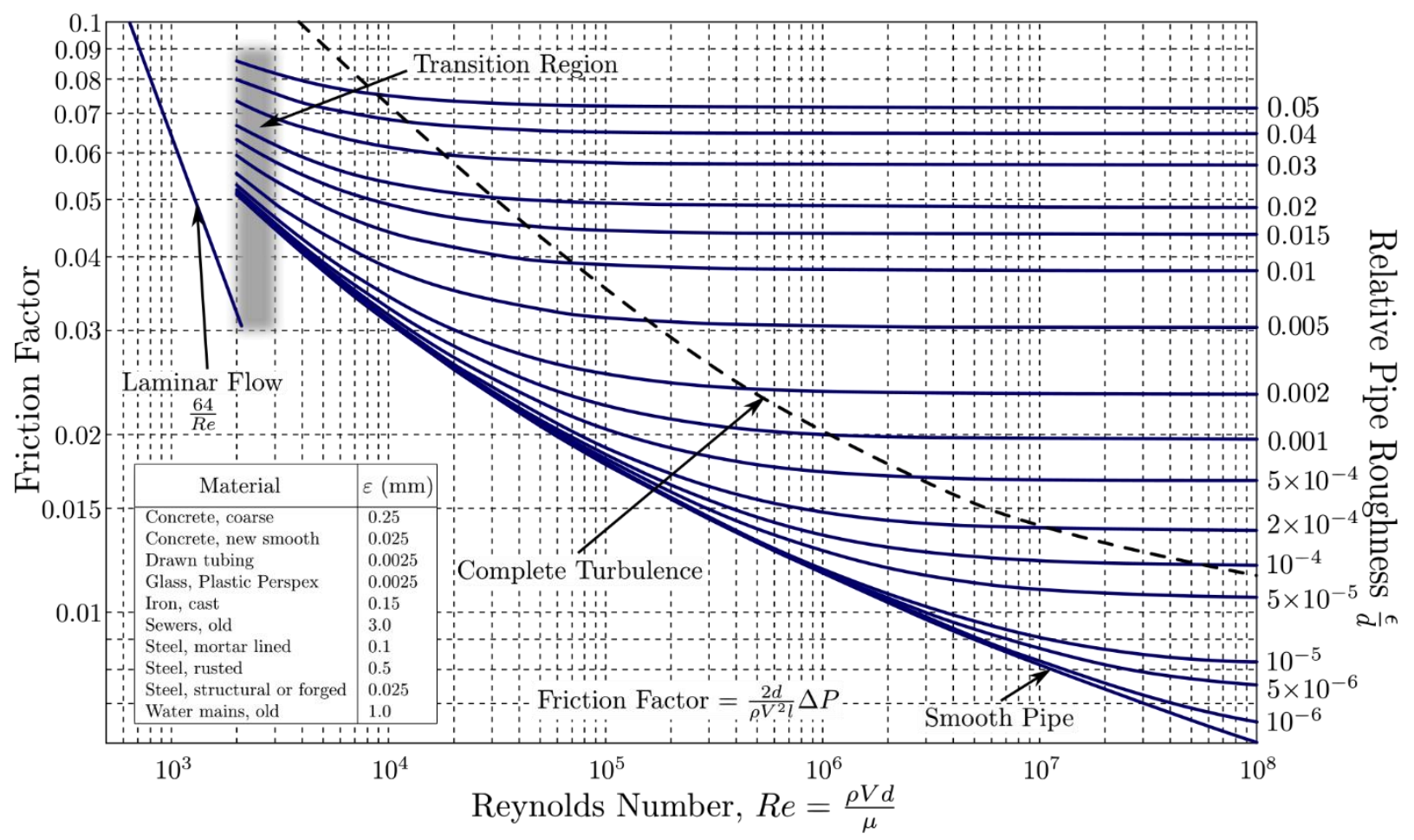

Fig 4. Moody diagram

Raw Data

Table 1

\begin{tabular}{|c|c|c|c|c|c|c|}
\hline \multirow{2}{*}{ Flow rate } & \multicolumn{2}{|c|}{ Pipe 1 } & \multicolumn{2}{c|}{ Pipe 2 } & \multicolumn{2}{c|}{ Pipe 3 } \\
\cline { 2 - 7 } & $P_{\text {in }}(\mathrm{psi})$ & $P_{\text {out }}(\mathrm{psi})$ & $P_{\text {in }}(\mathrm{psi})$ & $P_{\text {out }}(\mathrm{psi})$ & $P_{\text {in }}(\mathrm{psi})$ & $P_{\text {out }}(\mathrm{psi})$ \\
\hline$Q_{1}$ & & & & & & \\
\hline$Q_{2}$ & & & & & & \\
\hline$t_{1}$ & & $t_{2}$ & & \multicolumn{2}{|c|}{ Volume of reservoir $(V)$} & \\
\hline
\end{tabular}




\section{Analyzed Data}

Calculate the fluid velocity $(V)$ through each pipe. Determine the slope of the energy grade line $(S)$ for each of the pipes. Determine the friction coefficients (i.e., $f, C_{H W}$, and $n$ ) for each of the pipes (Sarker, 2021e). Compare the measured friction coefficients with the theoretical values. Determine the total head loss through pipe 3. Determine the head loss due to pipe friction using friction coefficients obtained from the pipe friction experiments. Calculate the minor head loss (Note: minor loss $=$ total loss - major loss). Compare the measured minor head loss with the one using minor loss coefficients obtained from theory.

Table 2 - Major loss due to pipe friction

\begin{tabular}{|c|c|c|c|c|c|c|c|c|c|}
\hline Pipe & Trial & $\begin{array}{c}Q \\
\left(f t^{3} / s\right)\end{array}$ & $H_{L}=\frac{\left(P_{\text {in }}-P_{\text {out }}\right)}{\gamma} \mathrm{ft}$ & $\begin{array}{c}v \\
(f t / s)\end{array}$ & $S$ & $R_{h}(\mathrm{ft})$ & $f$ & $C_{H W}$ & $n$ \\
\hline \multirow{2}{*}{$\# 1$} & $Q_{1}$ & & & & & & & & \\
\hline & $Q_{2}$ & & & & & & & & \\
\hline \multirow{2}{*}{$\# 2$} & $Q_{1}$ & & & & & & & & \\
\cline { 2 - 10 } & $Q_{2}$ & & & & & & & & \\
\hline
\end{tabular}

Table 3 - Minor losses due to fittings

\begin{tabular}{|c|c|c|c|c|c|c|c|c|}
\hline Pipe & Trial & $\begin{array}{l}Q \\
\left(f t^{3}\right. \\
/ s)\end{array}$ & $\begin{array}{c}H_{L}= \\
\frac{\left(P_{\text {in }}-P_{\text {out }}\right)}{\gamma} \\
\mathrm{ft}\end{array}$ & $\begin{array}{c}v \\
(f t / s)\end{array}$ & $\begin{array}{c}\text { Pipe } \\
\text { friction } \\
\text { loss }(f t)\end{array}$ & $\begin{array}{c}\text { Measured } \\
\text { minor } \\
\text { loss }(f t)\end{array}$ & $\begin{array}{c}\text { Theoretical } \\
\text { minor } \\
\text { loss }(f t)\end{array}$ & $\begin{array}{c}\text { Relative } \\
\text { Error } \\
(\%)\end{array}$ \\
\hline \multirow{2}{*}{ \#3 } & $Q_{1}$ & & & & & & & \\
\hline & $Q_{2}$ & & & & & & & \\
\hline
\end{tabular}




\section{Lab Questions}

1. What are the factors upon which the frictional loss in a pipe depends?

2. Discuss the relation between fluid friction and velocity of a pipe for different flow condition?

3. Regarding the bottom pipe (Pipe \#3), compare the measured minor head loss with its theoretical value (by using minor loss coefficients obtained from references).

4. Discuss the trends of your data including any irregularities. For example, for the same discharge trial, see the variation of friction loss on pipes having different material and lengths. For Pipe \#3, how is the head loss influenced when increasing the discharge?

5. What is the practical use of the experiment in real world?

\section{Report format}

Students are expected to submit the lab report in the following format. Report will be evaluated in $100 \%$. The distribution of total marks is shown in bracket in the table below. Please submit a soft copy (pdf) in the webcourse assignment section. You can send any questions regarding Lab by webcourses inbox. Please prepare a pdf file in the following format and mention the course number in the subject line.

“CWR4202CLab-LastName-FirstName-Labno.pdf” (For example, CWR4202CLab-Sarker Shiblu-Lab05.pdf)

\begin{tabular}{|c|c|c|}
\hline & Cover Page & $\begin{array}{l}\text { Please provide the course number, course name, experiment name, } \\
\text { your name and submission date. }\end{array}$ \\
\hline 1 & Introduction $(5 \%)$ & $\begin{array}{l}\text { Not more than } 200 \text { words. It may include the background and scope } \\
\text { of the experiment. }\end{array}$ \\
\hline 2 & Objective $(5 \%)$ & Please formulate the main objective (goal, aim) of the experiment. \\
\hline 3 & Procedure $(5 \%)$ & $\begin{array}{l}\text { Please provide step by step procedure how the experiment can be } \\
\text { done. }\end{array}$ \\
\hline 4 & $\begin{array}{l}\text { Experimental data } \\
(10 \%)\end{array}$ & $\begin{array}{l}\text { Please present the raw data in tabular format mentioning the proper } \\
\text { unit and symbol. }\end{array}$ \\
\hline 5 & $\begin{array}{l}\text { Sample calculation } \\
(20 \%)\end{array}$ & $\begin{array}{l}\text { In this section, please present the calculation of different parameters } \\
\text { from the experimental data along with mathematical equations } \\
\text { provided in the manual. }\end{array}$ \\
\hline 6 & Results (15\%) & $\begin{array}{l}\text { Please present your results in tabular format. If it is required to } \\
\text { present it by graph, chart etc., please put those in this section. }\end{array}$ \\
\hline
\end{tabular}




\begin{tabular}{|l|l|l|}
\hline 7 & $\begin{array}{l}\text { Answer to the lab } \\
\text { questions (20\%) }\end{array}$ & $\begin{array}{l}\text { Please provide the answers to the lab questions. Please try to answer } \\
\text { what is asked for. }\end{array}$ \\
\hline 8 & Discussion (15\%) & $\begin{array}{l}\text { In this part, please discuss your results. If any kind of error, unusual } \\
\text { results etc. are found, please discuss it in this section. Try to be } \\
\text { precise and write to the point which is asked for. Also write the } \\
\text { practical value of the experiment. }\end{array}$ \\
\hline 9 & Conclusions (5\%) & Please write a short conclusion (not more than 50 words). \\
\hline
\end{tabular}




\section{Chapter 6: Pipes in Series and Parallel}

\section{Purpose}

The objective of this experiment is to show the relationships common to series and parallel piping systems.

\section{Equipment}

1. Water storage reservoir

2. Pump

3. Flow meter

4. Pipes (clear PVC, sand lined PVC, and opaque PVC)

Pipe diameter $=1$ inch

Pipe length $=7.8 \mathrm{ft}$

5. Flow network panels

6. Pressure gauge

7. Timer

\section{General}

In many pipe systems there is more than one pipe involved. The governing mechanisms for the flow in multiple pipe systems are the same as for the single pipe systems. However, because of the numerous unknowns involved, additional complexities may arise in solving for the flow in multiple pipe systems. The simplest multiple pipe systems can be classified into series or parallel flows. The terminology is similar to that used in electrical circuits. Indeed, an analogy between fluid and electrical circuits is often made as follows. In a simple electrical circuit, there is a balance between the voltage $\mathrm{V}$, current $i$, and resistance $R$ as given by Ohms law:V $=i R$. In a fluid circuit there is a balance between the head loss $h_{L}$ the flowrate $Q$, and the flow resistance $R$ as given in terms of the friction factor (including major and minor loss coefficients) $K$. For a simple flow it can be written as:

$$
h_{L}=Q \mathrm{~K}
$$

Darcy Weisbach proposed the formula for the turbulent flow,

$$
h_{L}=f \frac{L}{D} \frac{v^{2}}{2 g}
$$

Where, $f=$ friction coefficient, $L=$ Length of pipe, $v=$ velocity of pipe, $D=$ Diameter of the pipe. For laminar flow head loss $\left(h_{L}\right)$ given by Hagen-Poiseuille is:

$$
h_{L}=\frac{32 \mu L v}{\rho g D^{2}}
$$


For laminar flow the striking feature of the equation is that it involves no empirical coefficient or experimental factors of any kind, except for the physical properties of fluid such as, viscosity, and density. So, for laminar flow the above equation can be written in following form:

$$
h_{L}=Q \mathrm{~K}
$$

\section{Practical application}

Flow through pipes in series and parallel experiment gives a notion of pipe system mechanism and design of pipe network system in real word. Besides pipes it has wide range of use in natural and manmade network system (Reza et al., 2014; Sarker, 2021a, 2021c, 2021e; Sarker et al., 2018, 2019a, 2019b; Sarker \& Singh, 2017).

\section{Objectives}

1. To understand the series and parallel flow in a pipe system.

2. To check the mass and energy balance of the system.

3. To determine the friction coefficients for the Darcy-Weisbach $(f)$ equations.

Experimental setup

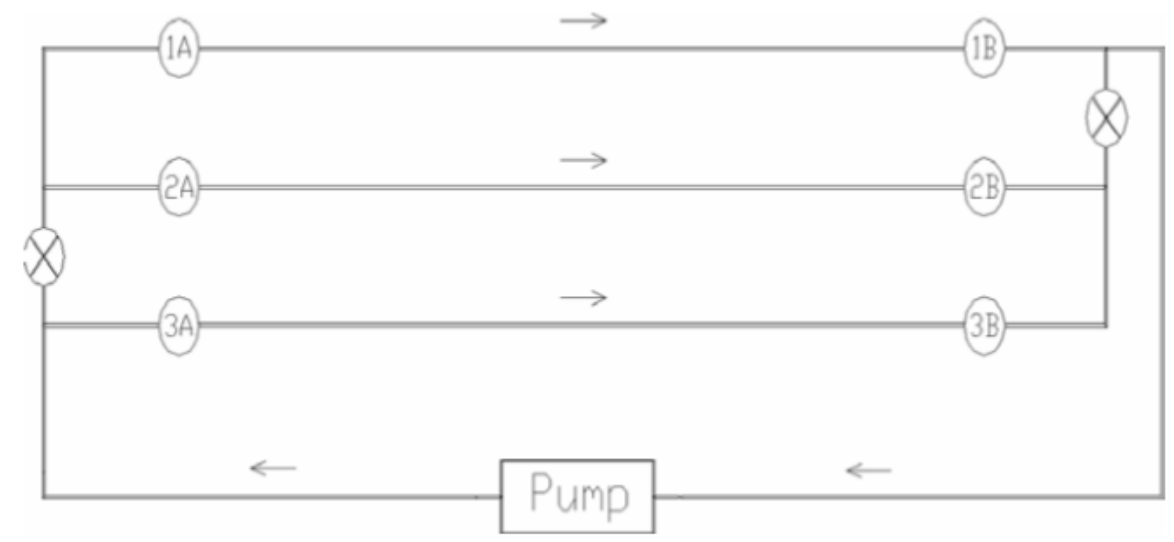

Fig 1. Experimental pipe system

\section{Procedure}

1. Set up the flow network system, as shown in the diagram below, so that the water will circulate from the supply reservoir through the pipe network and back to the supply reservoir.

2. Fill the supply reservoir with water. 


\section{Pipe in Series}

1. Close both connector valves (i.e., large valve on each side of the system). Open valves A and B for each of the pipes so that the water flow is not restricted in the system.

2. Turn on the pump. Allow sufficient time for the air to escape from the system.

3. Insert the pressure gauge onto the pressure tap located near valve A and then valve B. Read the gauge pressures. Do this for all pipes in the system.

4. Measure the flow rate.

5. Change the flow rate and repeat steps $3 \& 4$.

6. Turn off the pump.

Pipes in Parallel

1. Open both connector valves. Make sure the valves A and B on each pipe are open.

2. Turn on the pump. Allow sufficient time for the air to escape from the system.

3. Insert the pressure gauge onto the pressure tap located near valve A and then valve B. Read the gauge pressures. Do this for all pipes in the system.

4. Change the flow rate and repeat steps $2 \& 3$.

5. Turn off the pump.

\section{Theory}

The main differences between the solution methods used to solve electrical circuit problems and those for fluid circuit problems lie in the fact that Ohms law is a linear equation, while the fluid equations are generally nonlinear. When the pipes are connected in seris, the the flow rate through the entire system remains constant regardless of the diameters of the individual pipes in the system. This is a natural consequence of the conservation of mass principle for steady incompressible flow. The total head loss in the system, including the sum of the head losses in individual pipe in the system, including the mirror losses.

Mass Balance: $Q=Q_{1}=Q_{2}=Q_{3}$

Energy Balance: $H_{L}=H_{L 1}+H_{L 2}+H_{L 3}$

On the other hand, for a pipe that branches out into two (or more) parallel pipes and then rejoins at a junction downstream, the total flow rate is the sum of the flow rates in the individual pipes. 


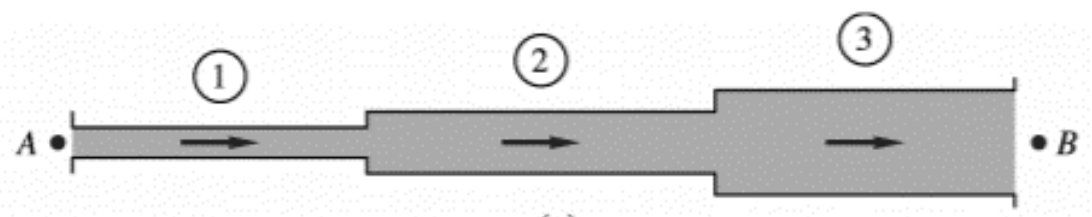

(a)

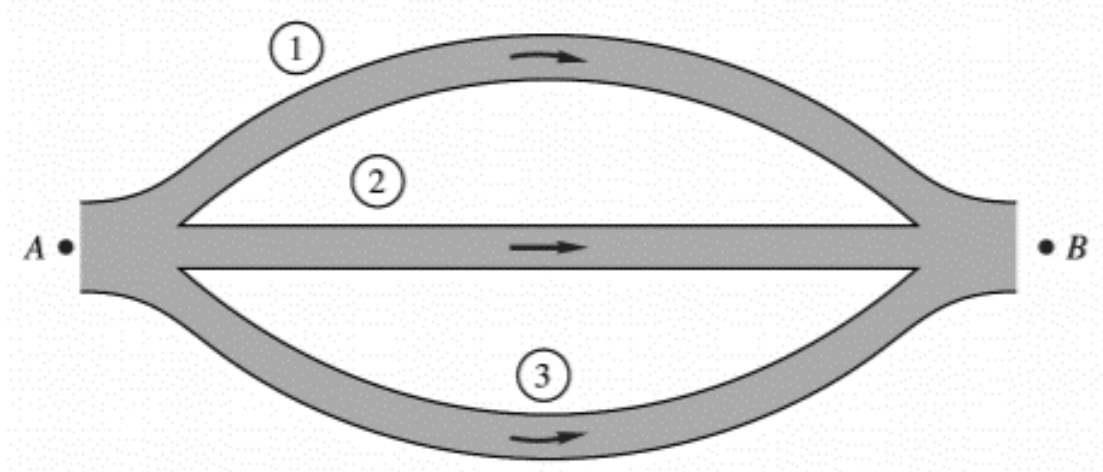

(b)

Fig 2. Series (a) and parallel (b) pipe system

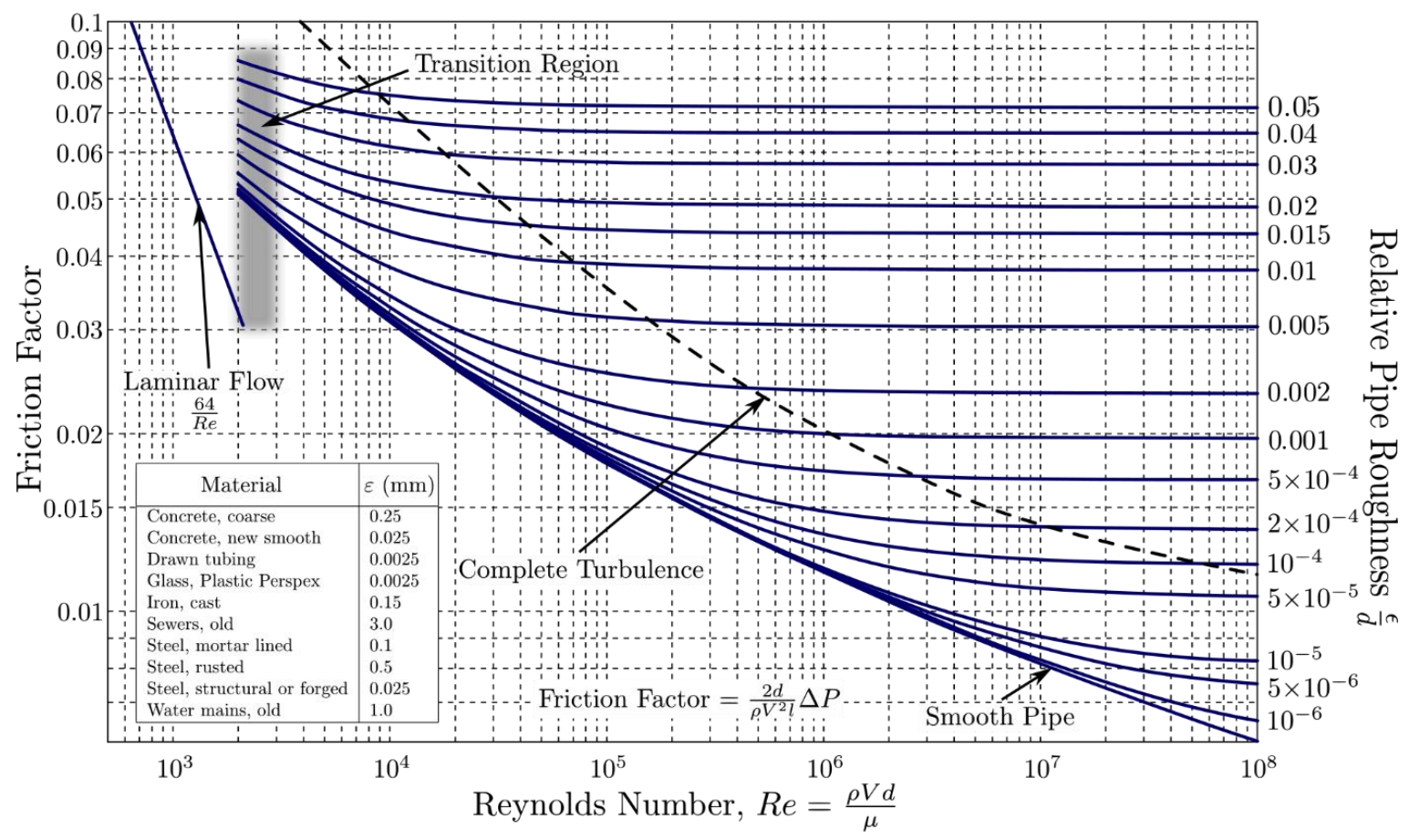

Fig 3. Moody diagram

And the head loss in each individual pipe connected in parallel must be the same since the governing equations for parallel pipes are: 
Mass Balance: $Q=Q_{1}+Q_{2}+Q_{3}$

Energy Balance: $H_{L}=H_{L 1}=H_{L 2}=H_{L 3}$

Darcy-Weisbach friction factor $f$ can be used as the hydraulic resistance $(K)$. Moody diagram is a curve that relates the Darcy-Weisbach friction factor $f$, Reynolds number $R_{e}$, and surface roughness for fully developed flow in a circular pipe (see figure 3).

Raw Data

Table 1: Pipes in Series

\begin{tabular}{|c|c|c|c|c|c|c|}
\hline \multirow{2}{*}{ Flow rate } & \multicolumn{2}{|c|}{ Pipe 1} & \multicolumn{2}{|c|}{ Pipe 2} & \multicolumn{2}{|c|}{ Pipe 3} \\
\hline & $P_{\text {in }}(\mathrm{psi})$ & $P_{\text {out }}(\mathrm{psi})$ & $P_{\text {in }}(\mathrm{psi})$ & $P_{\text {out }}(\mathrm{psi})$ & $P_{\text {in }}(\mathrm{psi})$ & $P_{\text {out }}(\mathrm{psi})$ \\
\hline$Q_{1}$ & & & & & & \\
\hline$Q_{2}$ & & & & & & \\
\hline$t_{1}$ & & $t_{2}$ & & Volume of & ervoir $(V)$ & \\
\hline
\end{tabular}

Table 2: Pipes in Parallel

\begin{tabular}{|c|c|c|c|c|c|c|}
\hline \multirow{2}{*}{ Flow rate } & \multicolumn{2}{|c|}{ Pipe 1} & \multicolumn{2}{|c|}{ Pipe 2} & \multicolumn{2}{|c|}{ Pipe 3} \\
\hline & $P_{\text {in }}(\mathrm{psi})$ & $P_{\text {out }}(\mathrm{psi})$ & $P_{\text {in }}(\mathrm{psi})$ & $P_{\text {out }}(\mathrm{psi})$ & $P_{\text {in }}(\mathrm{psi})$ & $P_{\text {out }}(\mathrm{psi})$ \\
\hline$Q_{1}$ & & & & & & \\
\hline$Q_{2}$ & & & & & & \\
\hline$t_{1}$ & & $t_{2}$ & & Volume of & ervoir $(V)$ & \\
\hline
\end{tabular}

\section{Analyzed Data}

Determine the head loss through each pipe. Determine the total head loss through the pipe network. Evaluate the friction coefficient (f) for each of the pipes. Determine the head loss through each pipe. The head loss through each pipe should be equal. If they are not, explain why. Knowing each pipe length, diameter, head loss, and friction coefficient (f), calculate the flow rate through each of the pipes. Sum the flow rates calculated to find the total flow rate through the system. Does this 
calculated flow rate match the flow rate measured in the lab? Develop the following tables for each flow rate $\left(Q_{1} \& Q_{2}\right)$.

Mass and energy balance check for $Q_{1}$ :

Table 3 - Pipes in Series

\begin{tabular}{|c|c|c|c|c|}
\hline Pipe & $\begin{array}{c}Q_{\text {mes }} \\
\left(f t^{3} / s\right)\end{array}$ & $H_{L}=\frac{\left(P_{\text {in }}-P_{\text {out }}\right)}{\gamma} \mathrm{ft}$ & $\begin{array}{c}v \\
(f t / s)\end{array}$ & $f$ \\
\hline$\# 1$ & & & & \\
\hline$\# 2$ & & & & \\
\hline$\# 3$ & & & & \\
\hline & & $\sum H_{L}=$ & & \\
\hline
\end{tabular}

Table 4 - Pipes in Parallel

\begin{tabular}{|c|c|c|c|c|}
\hline Pipe & $H_{L}=\frac{\left(P_{\text {in }}-P_{\text {out }}\right)}{\gamma} \mathrm{ft}$ & $f$ & $\begin{array}{c}v \\
(f t / s)\end{array}$ & $\begin{array}{c}Q_{\text {cal }} \\
\left(f t^{3} / s\right)\end{array}$ \\
\hline$\# 1$ & & & & \\
\hline$\# 2$ & & & & \\
\hline$\# 3$ & & & & \\
\hline & & & & $\sum Q=$ \\
\hline
\end{tabular}

Mass and energy balance check for $Q_{2}$ : 
Table 5 - Pipes in Series

\begin{tabular}{|c|c|c|c|c|}
\hline Pipe & $\begin{array}{c}Q_{\text {mes }} \\
\left(f t^{3} / s\right)\end{array}$ & $H_{L}=\frac{\left(P_{\text {in }}-P_{\text {out }}\right)}{\gamma} \mathrm{ft}$ & $\begin{array}{c}v \\
(f t / s)\end{array}$ & $f$ \\
\hline$\# 1$ & & & & \\
\hline$\# 2$ & & & & \\
\hline$\# 3$ & & & & \\
\hline & & $\sum H_{L}=$ & & \\
\hline
\end{tabular}

Table 6 - Pipes in Parallel

\begin{tabular}{|c|c|c|c|c|}
\hline Pipe & $H_{L}=\frac{\left(P_{\text {in }}-P_{\text {out }}\right)}{\gamma} \mathrm{ft}$ & $f$ & $v$ & $Q_{\text {cal }}$ \\
\hline$\# 1$ & & & & \\
\hline$\# 2$ & & & & \\
\hline$\# 3$ & & & & \\
\hline & & & & $\sum Q=$ \\
\hline
\end{tabular}

\section{Lab Questions}

1. For the pipes in parallel, the head loss through each pipe should be equal. If the head losses in the three pipes are unequal, state possible reasons for such a discrepancy.

2. The sum of the calculated flow rates should be equal to the total measured flow rate through the system. If the two flow rates above are unequal, state possible reasons that explain this discrepancy.

3. What is the practical use of the experiment in real world? 


\section{Report format}

Students are expected to submit the lab report in the following format. Report will be evaluated in $100 \%$. The distribution of total marks is shown in bracket in the table below. Please submit a soft copy (pdf) in the webcourse assignment section. You can send any questions regarding Lab by webcourses inbox. Please prepare a pdf file in the following format and mention the course number in the subject line.

"CWR4202CLab-LastName-FirstName-Labno.pdf” (For example, CWR4202CLab-Sarker Shiblu-Lab06.pdf)

\begin{tabular}{|l|l|l|}
\hline & Cover Page & $\begin{array}{l}\text { Please provide the course number, course name, experiment name, } \\
\text { your name and submission date. }\end{array}$ \\
\hline 1 & Introduction (5\%) & $\begin{array}{l}\text { Not more than } 200 \text { words. It may include the background and scope } \\
\text { of the experiment. }\end{array}$ \\
\hline 2 & Objective (5\%) & Please formulate the main objective (goal, aim) of the experiment. \\
\hline 3 & Procedure (5\%) & $\begin{array}{l}\text { Please provide step by step procedure how the experiment can be } \\
\text { done. }\end{array}$ \\
\hline 4 & $\begin{array}{l}\text { Experimental data } \\
(10 \%)\end{array}$ & $\begin{array}{l}\text { Please present the raw data in tabular format mentioning the proper } \\
\text { unit and symbol. }\end{array}$ \\
\hline 5 & $\begin{array}{l}\text { Sample calculation } \\
(20 \%)\end{array}$ & $\begin{array}{l}\text { In this section, please present the calculation of different parameters } \\
\text { from the experimental data along with mathematical equations } \\
\text { provided in the manual. }\end{array}$ \\
\hline 6 & Results (15\%) & $\begin{array}{l}\text { Please present your results in tabular format. If it is required to } \\
\text { present it by graph, chart etc., please put those in this section. }\end{array}$ \\
\hline 7 & $\begin{array}{l}\text { Answer to the lab } \\
\text { questions (20\%) }\end{array}$ & $\begin{array}{l}\text { Please provide the answers to the lab questions. Please try to answer } \\
\text { what is asked for. }\end{array}$ \\
\hline 8 & Discussion (15\%) & $\begin{array}{l}\text { In this part, please discuss your results. If any kind of error, unusual } \\
\text { results etc. are found, please discuss it in this section. Try to be } \\
\text { precise and write to the point which is asked for. Also write the } \\
\text { practical value of the experiment. }\end{array}$ \\
\hline 9 & Conclusions (5\%) & \begin{tabular}{l} 
Please write a short conclusion (not more than 50 words). \\
\hline
\end{tabular} \\
\hline
\end{tabular}




\section{Chapter 7: Pipe network design and analysis}

\section{Lab instructions}

Please BRING a portable storage device (i.e., PEN DRIVE, External HDD etc). Please DOWNLOAD the system layout map from web course and STORE it in your storage device before coming to the class.

\section{Problem Definition}

The layout below is that of a proposed youth educational camp, part of which will receive its water supply from an overhead tank. You are to design the water distribution system for the subdivision to the left of the layout shown, using WaterCad. The tank from which the subdivision will be fed has bottom and top elevations of $700 \mathrm{ft}$ and $730 \mathrm{ft}$, respectively. This is based on an average daily demand of $40 \mathrm{gpm}$.

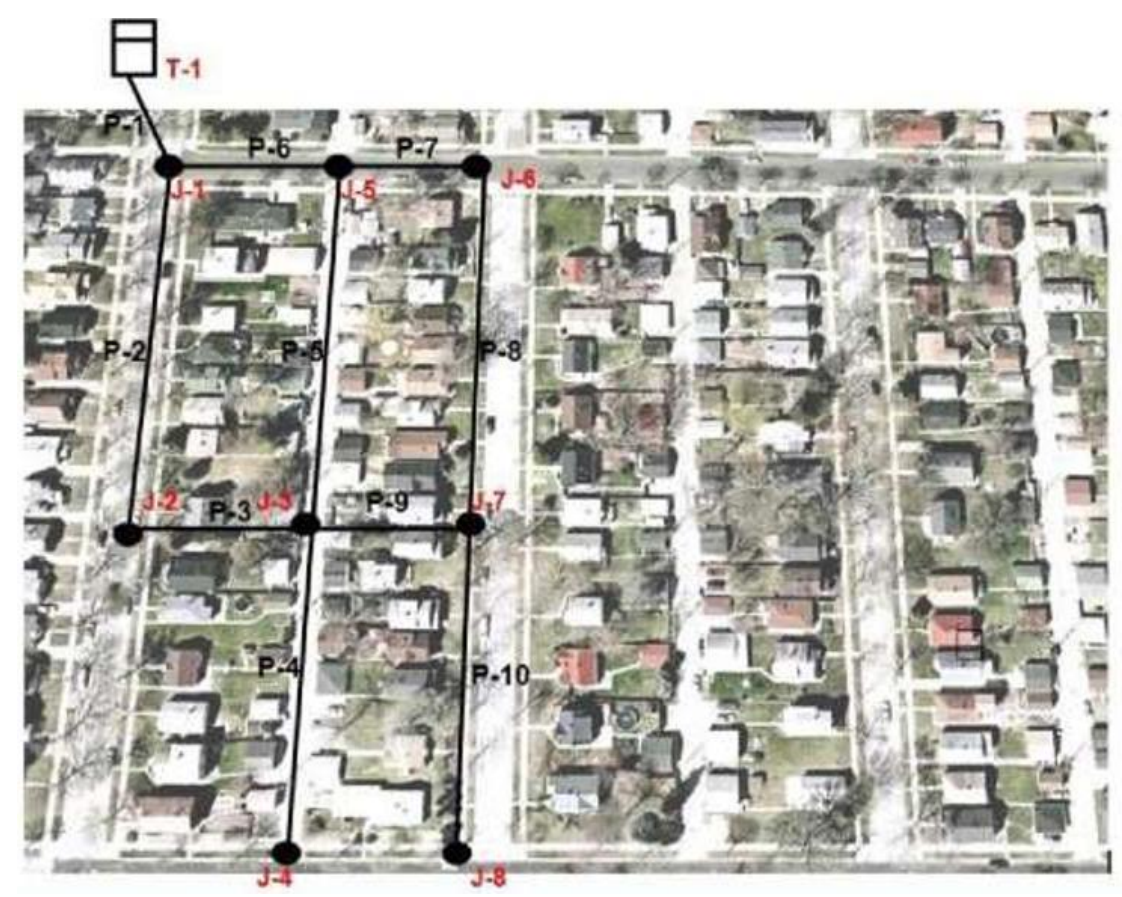

\section{Procedure (Program Execution)}

Start by clicking on the WaterCad V8 Icon and selecting Create New Project from the initial popup menu (Sarker, 2021d).

Click on the Tools tab, select Options and then choose Project. Make sure that pipe lengths are rounded off to the nearest foot. Click on the Drawing, select schematic drawing mode, and adjust annotation multipliers including symbol size and text height (set multiplier to 5). Go to Units and select the US system. Click OK and close the Options window. 
Choose the View Tab and select Prototypes. This will open the Prototype Manager, which lets you assign general properties to the elements you want. Right click on pipe and create a new prototype for the pipe elements. Click on properties: enter 6-in diameter, select PVC material, associated with a friction factor of Hazen-Williams of 150 from the build-in materials library. Under the userdefined length for pipes, select "True". Close the window.

Next, click on junction and create a new prototype for the junctions. Select Demand Demand Collection and right click on the heading of the base flow column and choose Global Edit. Then, select operation as Set, and type in the value of 40 as a global demand assigned to all junctions. If necessary, click again on the heading of the demand column, select Units and Formatting, and change the units of the global flow to gal/min (gpm). Close the window and at the end the Prototype Manager.

From the bottom left column, click on Background Layers: NewFile. Browse to find Layout 1 on Webcourses or on your desktop. Click OK to keep its default properties and save the project onto a disk. You may need to zoom-extents to see the background layer. If you find the image too dark, you may increase its transparency to make the image brighter.

Construct a pipe distribution system for the given subdivision, according to the diagram provided. With the help of Element toolbar, create a tank, pipes and junctions. If you want to create a pipe with bends, right click on the selected pipe, select bend, add bends and snap on the desired point to create the bend. Make sure, under the element symbology, that all element labeling is clicked and keep labels consistent with the one of the diagrams.

Because you did not locate the tank exactly and did not give the pipes their exact lengths, select FlexTables, Pipe Table and give the pipe 1 a user defined length of $410 \mathrm{ft}$. Change all pipes in your system to the indicated lengths in the following table.

\begin{tabular}{|c|c|}
\hline Pipe & Length (ft) \\
\hline P-1 & 410 \\
\hline P-2 & 560 \\
\hline P-3 & 300 \\
\hline P-4 & 545 \\
\hline P-5 & 560 \\
\hline P-6 & 600 \\
\hline P-7 & 280 \\
\hline
\end{tabular}




\begin{tabular}{|c|c|}
\hline P-8 & 560 \\
\hline P-9 & 280 \\
\hline P-10 & 545 \\
\hline
\end{tabular}

Next, select Junction Table from FlexTables. Enter the elevations for each node from the table below.

\begin{tabular}{|c|c|}
\hline Junction & Elevation (ft) \\
\hline J-1 & 620 \\
\hline J-2 & 560 \\
\hline J-3 & 560 \\
\hline J-4 & 525 \\
\hline J-5 & 580 \\
\hline J-6 & 618 \\
\hline J-7 & 560 \\
\hline J-8 & 525 \\
\hline
\end{tabular}

Double-click on the tank, select the Physical heading and give the circular section a diameter of $60 \mathrm{ft}$. Then, select the Operating range heading and give minimum, initial and maximum elevations of 680,715 and $730 \mathrm{ft}$ respectively.

Now you are ready to run the model. Click on Validate icon to make sure the data is ok; if you have no errors you will get the "no problems were found" message box. Click on the Compute (green $\rightarrow$ ) icon to start running the model. When the run is complete, look at the status log and then close the status log box.

Select FlexTables, Junction Table, and examine the pressure and HGL. Similarly examine the pipe attributes by choosing FlexTables, Pipe Table. Complete the following table based on your run. Make sure your units are consistent with those on the answer table (consider the units consistency). If needed, click on the heading of the head loss gradient, select Units and Formatting, and change the units to $\mathrm{ft} / 1000 \mathrm{ft}$ length. Save your work as DESIGN (see details in Sarker, n.d.-a). 


\section{Summary Table}

\begin{tabular}{|c|c|}
\hline Model Run Results & Result \\
\hline Pressure at J-1 (psi) & \\
\hline Pressure at J-3 (psi) & \\
\hline Pressure at J-7 (psi) & \\
\hline HGL at J-5 (ft) & \\
\hline Velocity in P-1 (ft/s) & \\
\hline Velocity in P-6 (ft/s) & \\
\hline Discharge in P-2 (gpm) & \\
\hline Discharge in P-10 (gpm) & \\
\hline Which pipe with highest HGL slope? & \\
\hline HGL Slope in pipe above (ft/1000 ft) & \\
\hline
\end{tabular}

\section{Lab Questions}

1. In this exercise, $\mathrm{PVC}$ is used as pipe material. If it is decided to change the material to "cast iron', what is the impact in the pipe system? Please prepare a summary table for cast iron and compare and discuss the results with PVC material.

2. What are the main considerations for Hardy Cross method to design pipe network system? Explain with example.

3. Which junction has the highest pressure? Why?

4. What properties of the pipe network would you consider in your design to improve the performance of the system?

5. Discuss the split in flow between pipes 2 and 6 .

6 . What is the practical use of the experiment in real world?

\section{Report format}

Students are expected to submit the lab report in the following format. Report will be evaluated in $100 \%$. The distribution of total marks is shown in bracket in the table below. Please submit a soft copy (pdf) in the webcourse assignment section. You can send any questions regarding Lab by webcourses inbox. Please prepare a pdf file in the following format and mention the course number in the subject line. 
“CWR4202CLab-LastName-FirstName-Labno.pdf” (For example, CWR4202CLab-Sarker Shiblu-Lab07.pdf)

\begin{tabular}{|l|l|l|}
\hline & Cover Page & $\begin{array}{l}\text { Please provide the course number, course name, experiment name, } \\
\text { your name and submission date. }\end{array}$ \\
\hline 1 & Introduction (5\%) & $\begin{array}{l}\text { Not more than } 200 \text { words. It may include the background and scope } \\
\text { of the experiment. }\end{array}$ \\
\hline 3 & Objective (5\%) & Please formulate the main objective (goal, aim) of the experiment. \\
\hline 4 & $\begin{array}{l}\text { Summary of System } \\
\text { design (10\%) }\end{array}$ & $\begin{array}{l}\text { Please provide an overview of how the pipe network system is } \\
\text { implemented in WATERCAD. }\end{array}$ \\
\hline 5 & $\begin{array}{l}\text { Summary table } \\
(20 \%)\end{array}$ & $\begin{array}{l}\text { Please report your summary table for PVC pipe. If it is required to } \\
\text { present it by graph, chart etc., please put those in this section. }\end{array}$ \\
\hline 6 & $\begin{array}{l}\text { Answer to the lab } \\
\text { questions } \\
(20+20=40 \%)\end{array}$ & $\begin{array}{l}\text { Please provide the answers to the lab questions. Please try to answer } \\
\text { what is asked for. }\end{array}$ \\
\hline 7 & $\begin{array}{l}\text { Discussion (10\%) } \\
\text { Conclusions }(5 \%)\end{array}$ & $\begin{array}{l}\text { In this part, please discuss your results. If any kind of error, unusual } \\
\text { results etc. are found, please discuss it in this section. Try to be } \\
\text { precise and write to the point which is asked for. Also write the } \\
\text { practical value of the experiment. }\end{array}$ \\
\hline
\end{tabular}




\section{Chapter 8: Water Hammer effect in a pipe system}

Purpose

The purpose of the experiment is to familiarize and demonstrate the water hammer effect in the pipe system.

Equipment

1. Water Hammer circuit

2. Hydraulic bench

3. C7MK11 software

\section{General}

Water Hammer is a pressure surge or wave that occurs when there is a sudden momentum change of a fluid (the motion of a fluid is abruptly forced to stop or change direction) within an enclosed space. This commonly occurs in pipelines when a valve is closed suddenly at the end of a pipeline where the velocity of the fluid is high. The pressure wave created will propagate within the pipeline (Sarker, 2021b, 2021a).

Water hammer is caused by a change in fluid momentum. The most common cause of this change in momentum is sudden closure of a valve on a pipeline. When this occurs, a loud hammer noise can be produced, and vibrations can be sent through the pipe. The pressure wave produced from this event can cause significant damage to pipe systems. The large increase in pressure can cause pipes to crack and in some cases burst. It also causes cavitation within pipelines and if is severe enough can cause the pipeline to implode. Figure 1 show a damage caused by water hammer.
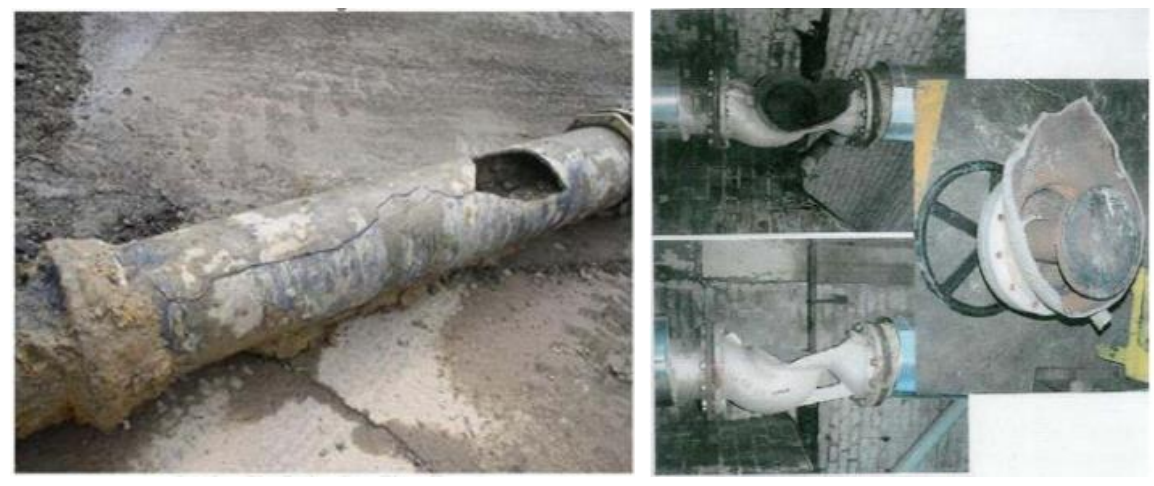

Fig 1. Pipelines damage caused by water hammer

Another instance that produces a water hammer effect is pump and turbine failure. When a pump fails, the sudden halt in flow will produce the momentum change causing the water hammer effect. This can also be seen in home plumbing systems when faucets are turned on and off suddenly. A loud hammer noise will be produced, and the plumbing will vibrate in most cases. Water hammer can be induced intentionally for various applications. A hydraulic ram can be created using a water hammer and is commonly used in mining practices to break through rock. In addition, the water hammer effect creates an increase in pressure within a pipeline and is then used to detected leaks 
within the pipeline. The increased pressure causes water to shoot out of the pipe at a leak site, which is then easily spotted. Despite water hammer being useful at time, it is generally an undesired phenomenon that must be considered when designing pipelines.

\section{Practical application}

Water hammering sound caused in pipe containing water when flow of water is passed through it. Water hammer analysis is a fundamental part of the design process of piping system for power plant or pipe network design.

Experimental setup

Schematic diagram: Figure 2 below shows the schematic diagram of the water hammer system.

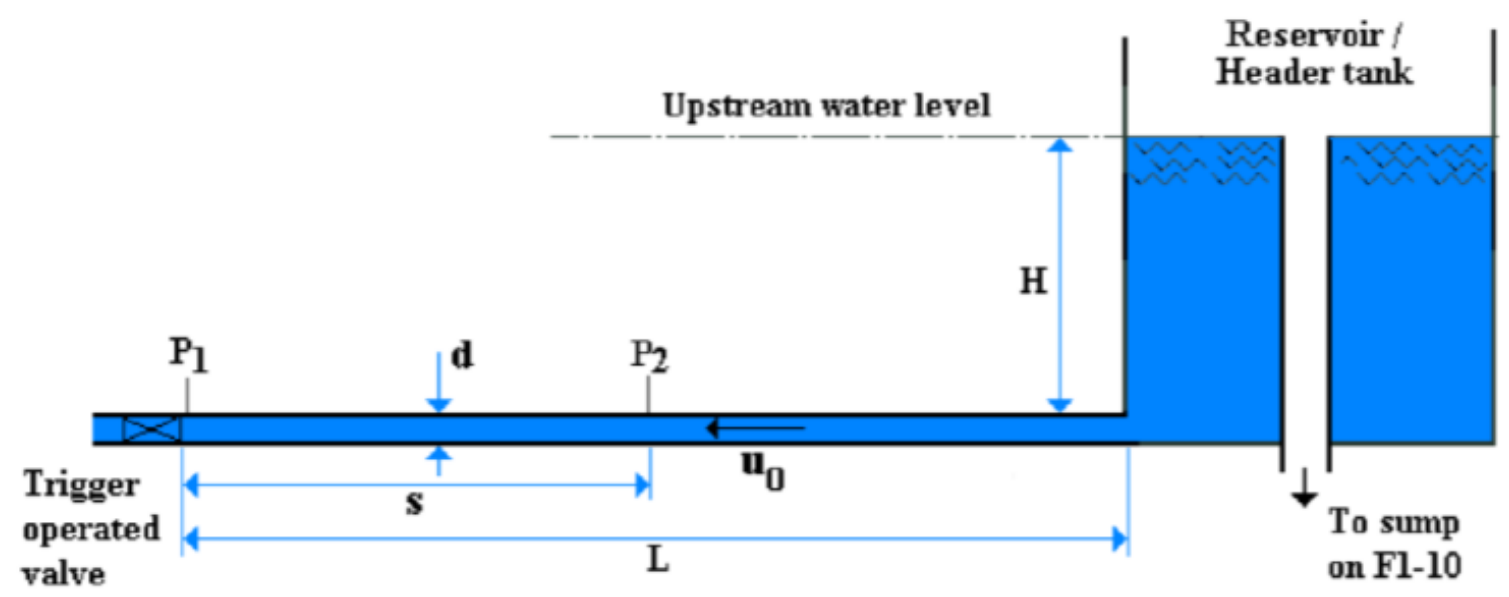

Fig 2. Schematic diagram of Water Hammer System

Figure 3 demonstrates the components of equipment set-up procedure for the experiment. The set up includes (see details in Sarker, n.d.-a):

1. Close the flow control valve in the pipe surge circuit.

2. Close the supply control valve on hydraulic bench.

3. Open the fast-acting valve on water hammer equipment by pushing the black knob inwards until it latches.

4. Close the flow control valve at the end of the water hammer circuit on water hammer equipment.

5. Switch on the pump using the switch on hydraulic bench.

6. Gradually open the supply control valve on hydraulic bench and allow the header tank to fill (indicated by the water level in the transparent surge shaft). 


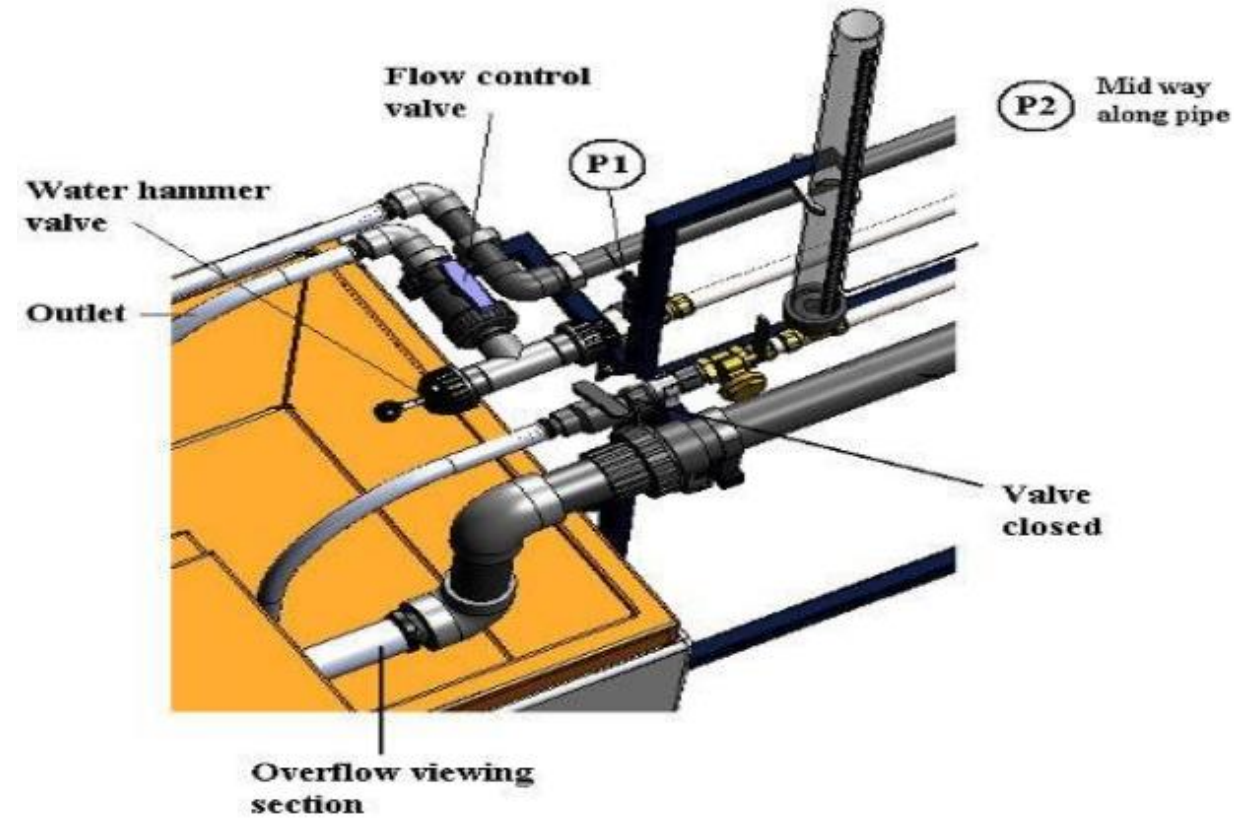

Fig 3. Components associated with the water hammer effect

7. When water starts to flow through the overflow viewing section (water has reached the level of the overflow inside the header tank) open the flow control valve alongside the fastacting valve. Water will flow through the test pipe and flush any trapped air from the test pipe. Water should flow steadily through the test pipe and exit into the volumetric tank via the flexible outlet tube.

8. If necessary, adjust the supply control valve on F1-10 until a steady trickle of water returns to the sump tank via the overflow.

\section{Procedure}

1. Load the C7-MKII software (Water hammer system) on the PC then load the Water Hammer Demonstration. The welcome screen should be displayed.

2. Before operating the software, it will be necessary to enable the USB virtual serial COM port. At the right-hand end of the top menu bar click the Start COM Session icon as shown to enable the port:

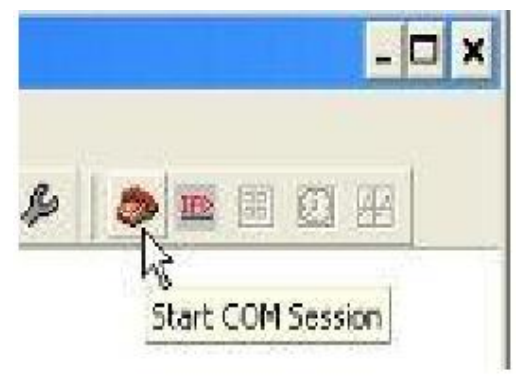


3. The Select Port window will open. Display the available COM ports by pulling down the menu:

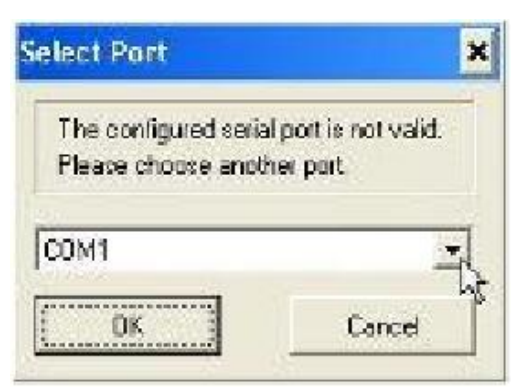

4. Highlight the last COM port in the list (highest number) then click OK to enable the port:
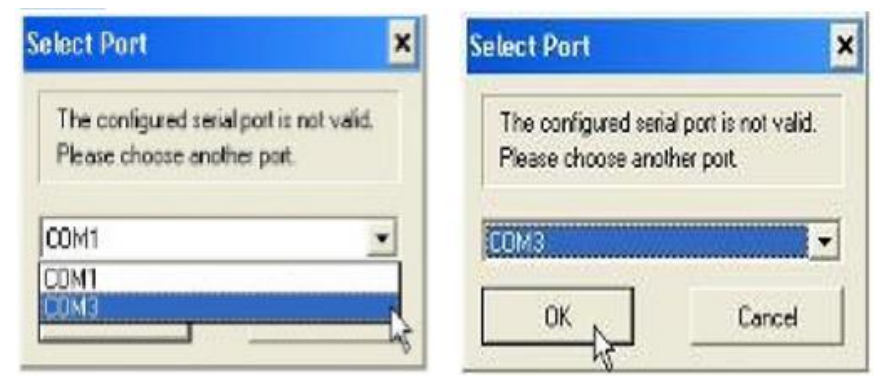

5. Confirm that the Serial Port has been enabled. If the Serial Port has been correctly enabled, then the virtual COM Port number followed by SE will be displayed in the bottom right hand corner.

6. If the wrong Serial Port has been selected, then the number of the port will be displayed but SE will not be displayed.

7. Display the mimic diagram and observe that readings from the two pressure sensors P1 and P2 in the water hammer circuit are displayed (indicating atmospheric pressure). Although very large in comparison with pipe surge pressures, the changes in pressure associated with water hammer only last for fractions of a second so the phenomena must be recorded using a virtual oscilloscope and viewed following the event and cannot be observed in real time.

8. Open the flow control fully then open the fast-acting valve (18) and the flow through the water hammer circuit to settle. The level in the surge shaft should remain high indicating the level in the reservoir. Confirm that a small flow of water is returning to the sump tank via the clear tube in the return pipe. If necessary, adjust the flow control valve on to maintain a small flow from the overflow.

9. Having loaded the Water Hammer exercise on the PC, the virtual oscilloscope will be enabled indicated by a message in the bottom left-hand corner of the screen: 


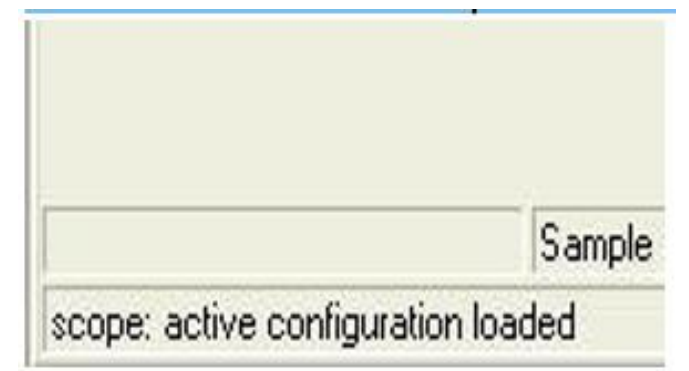

10. Note: If the virtual oscilloscope is not automatically enabled or it is required to change the settings associated with the oscilloscope then refer to the Operation section.

11. Click the Go icon the fast-acting valve within approximately 2 seconds.

12. Wait until the data has been recorded and processed then save the data obtained.

\section{Theory and Calculations}

Through the application of the momentum equation (Reza et al., 2014; Sarker, 2021a, 2021e)(Equation 1):

$$
\sum F=\rho Q\left(V_{2}-V_{1}\right)
$$

Where:

$$
F=\text { force }, \rho=\text { fluid density, } V_{1}=\text { initial fluid velocity, } V_{2}=\text { final fluid velocity }
$$

it can be seen from equation (1) that when $V_{2}$ falls below $V_{1}$, a negative force is created. This negative force forms a wave of increased pressure within a pipeline that propagates back toward the source of the flow and moves back and forth, to and from the source.

The wave speed, also known as celerity, is a function of the theoretical wave celerity, which is given by Equation 2.

$$
c^{\prime}=\sqrt{\frac{E_{v}}{\rho}} \ldots \ldots \ldots \ldots \ldots \ldots
$$

Where:

$$
c^{\prime}=\text { theoretical wave celerity, } E_{v}=\text { bulk modulus of elasticity of fluid, } \rho=\text { fluid density }
$$

The wave speed is also a function of the composite modulus of elasticity of the pipe fluid pipe system, the pipe diameter, pipe wall thickness, and modulus of elasticity of the pipe. Equation 3 solves for the speed of the pressure wave within a pipe. 


$$
c=\sqrt{\frac{c^{\prime}}{1+\left(\frac{E_{v} d}{\varepsilon E_{p}}\right)}} \ldots \ldots \ldots \ldots \ldots \ldots \ldots \ldots
$$

Where:

$c=$ celerity of pressure wave, $E_{v}=$ bulk modulus of elasticity of fluid, $d=$ pipe diameter, $\varepsilon=$ thickness of pipe walls, $E_{p}=$ modulus of elasticity of pipe, $c^{\prime}=$ theoretical wave celerity

The maximum change in pressure created from water hammer in a pipeline is derived from the momentum equation and results in Equation 4. Equation 6 is for rapid valve closure, which occurs when the time of closure it less than the pipe length divided by the wave celerity $t<L / c$.

$$
\Delta p=\rho c V_{0}
$$

Where:

$$
\Delta p=\text { change in pressure, } c=\text { wave celerity, } V_{0}=\text { initial velocity }
$$

The maximum pressure that will occur in the pipe is the original pressure within the pipe plus the change in pressure, as shown in Equation 5.

$$
p_{\max }=p_{0}+\Delta p
$$

Where:

$$
p_{\text {max }}=\text { maximum pressure }, p_{0}=\text { initial pressure }, \Delta p=\text { change in pressure }
$$

This pressure variation will change in cycles at times equal to $t=(2 \mathrm{~L} / \mathrm{C})$ for a rapid interruption of the flow. Over time, the pressure wave will decrease due to friction losses. Figure 4 demonstrates the pressure wave cycles within a pipe.

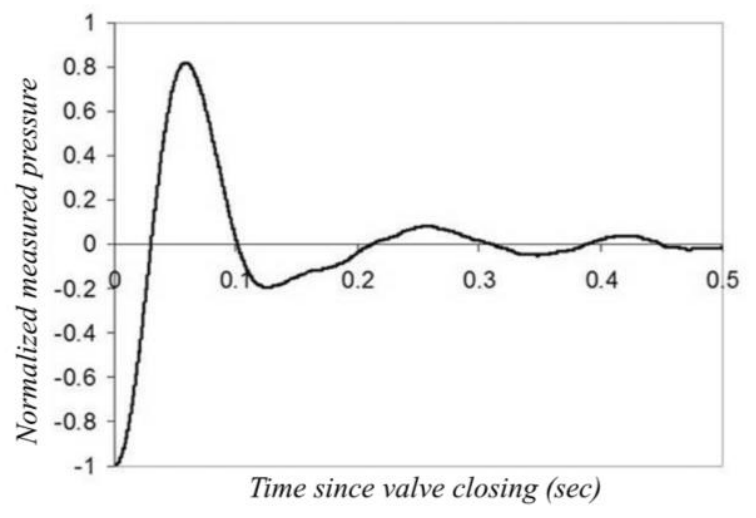

Fig 4. Exemplary pressure wave cycles within a pipe 
As shown in Figure 3, the pressure and velocity of the water at a given point within a pipe oscillate, while overall steadily decreasing as time passes.

For slow closure within a pipe $t>L / c$, the change in pressure can be found using Equation 6 .

$$
p_{\max }=p_{0}\left(\frac{N}{2}+\sqrt{\frac{N^{2}}{4}+N}\right)
$$

Where:

$$
\begin{gathered}
N=\frac{\rho L V_{0}}{p_{0} T_{v}}\left(\mathrm{~L}=\text { length of pipe, } \mathrm{T}_{\mathrm{v}}=\text { time to close }\right), p_{0}=\text { initial pressure, } \Delta p= \\
\text { change in pressure }
\end{gathered}
$$

\section{Raw Data}

Data table (Time, P1 and P2); generated by C7MK11 software. This data will be provided in the webcourses announcement.

\section{Analyzed Data}

Analyze the pressure transient obtained from pressure sensor P1 at the fast-acting valve. Display the traces from pressure sensors P1 and P2 on different axes to view the differences between the traces. Import the data table to Microsoft Excel and plot the experimental graph (Time vs P1 and P2 graph). Explain the theoretical and experimental (i.e. provided in webcourses) water hammer pressure wave. Usually theoretical and experimental water hammer pressure wave looks like as figure 5 .

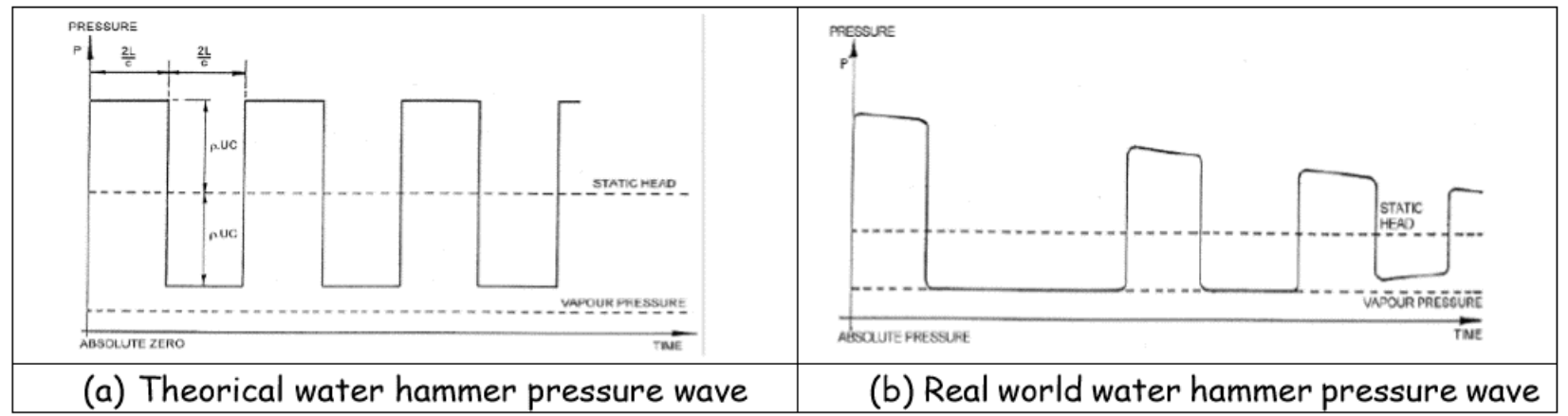

Fig 5. The theoretical and experimental water hammer pressure wave

\section{Lab Questions}

1. What is the practical use of this experiment?

2. How can we know whether there is a risk of water hammer or not?

3. Write the theoretical expression of calculating water hammer effect in a pipe. Explain each term of it. Which term of the expression has the most significant effect in real world?

4. Please explain the theoretical water hammer pressure wave with figure.

5. Please explain your water hammer pressure wave plot based on provided data. 


\section{Report format}

Students are expected to submit the lab report in the following format. Report will be evaluated in $100 \%$. The distribution of total marks is shown in bracket in the table below. Please submit a soft copy (pdf) in the webcourse assignment section. You can send any questions regarding Lab by webcourses inbox. Please prepare a pdf file in the following format and mention the course number in the subject line.

“CWR4202CLab-LastName-FirstName-Labno.pdf” (For example, CWR4202CLab-Sarker Shiblu-Lab08.pdf)

\begin{tabular}{|l|l|l|}
\hline & Cover Page & $\begin{array}{l}\text { Please provide the course number, course name, experiment name, } \\
\text { your name and submission date. }\end{array}$ \\
\hline 1 & $\begin{array}{l}\text { Introduction and } \\
\text { Objective (5\%) }\end{array}$ & $\begin{array}{l}\text { Not more than 200 words. It may include the background and main } \\
\text { goal of the experiment. }\end{array}$ \\
\hline 2 & $\begin{array}{l}\text { Theory and } \\
\text { Calculations (30\%) }\end{array}$ & $\begin{array}{l}\text { Please explain the clear concept of a water hammer effect in a pipe } \\
\text { system along with mathematical equations provided in the manual. }\end{array}$ \\
\hline 3 & $\begin{array}{l}\text { Experimental setup } \\
(5 \%)\end{array}$ & $\begin{array}{l}\text { Please provide the schematic diagram and software use for a water } \\
\text { hammer system. }\end{array}$ \\
\hline 4 & $\begin{array}{l}\text { Procedure (5\%) } \\
\text { Please provide step by step procedure how the experiment can be } \\
\text { done. }\end{array}$ \\
\hline 5 & $\begin{array}{l}\text { Graphs (Time vs P1 } \\
\text { and P2) (20\%) }\end{array}$ & $\begin{array}{l}\text { Please draw the curve for points P1 and P2 according to the data } \\
\text { provided in webcourses. }\end{array}$ \\
\hline 6 & Discussion (10\%) & Please discuss the plots. Why it is not like theoretical plot. \\
\hline 7 & $\begin{array}{l}\text { Lab questions } \\
(20 \%)\end{array}$ & $\begin{array}{l}\text { Please provide the answers to the lab questions. Please try to answer } \\
\text { what is asked for. }\end{array}$ \\
\hline 8 & Conclusions (5\%) & Please write a short conclusion (not more than 50 words). \\
\hline
\end{tabular}


References

Khan, I., Ahammad, M., \& Sarker, S. (2014). A Study on River Bank Erosion of Jamuna River Using GIS and Remote Sensing Technology. International Journal of Engineering Development and Research.

Reza, A. A., Sarker, S., \& Asha, S. A. (2014). AN APPLICATION OF 1-D MOMENTUM EQUATION TO CALCULATE DISCHARGE IN TIDAL RIVER: A CASE STUDY ON KALIGANGA RIVER. Tech. J. River Res. Inst.

Sarker, S. (2021a). A Short Review on Computational Hydraulics in the context of Water Resources Engineering. EngrXiv.

Sarker, S. (2021b). A Story on the Wave Spectral Properties of Water Hammer. EngrXiv. https://doi.org/https://doi.org/10.31224/osf.io/nhuzq

Sarker, S. (2021c). Investigating Topologic and Geometric Properties of Synthetic and Natural River Networks Under Changing Climatic. UCF STARS.

Sarker, S. (2021d). Pipe Network Design and Analysis: An Example with WaterCAD. EngrXiv. https://doi.org/https://doi.org/10.31224/osf.io/c3aky

Sarker, S. (2021e). Separation of Flood Plain Flow: 1-D Momentum Equation Solver. EngrXiv. https://doi.org/https://doi.org/10.31224/osf.io/sjcmv

Sarker, S., \& Singh, A. (2017). On the Topologic Properties of River Networks. In AGU Fall Meeting Abstracts (Vol. 2017, pp. IN33B--0128).

Sarker, S., Veremyev, A., Boginski, V., \& Singh, A. (2018). On critical nodes in river networks. In AGU Fall Meeting Abstracts (Vol. 2018, pp. EP33D-2446).

Sarker, S., Veremyev, A., Boginski, V., \& Singh, A. (2019a). critical nodes in River networks. Scientific Reports, 9(1), 11178.

Sarker, S., Veremyev, A., Boginski, V., \& Singh, A. (2019b). Spectral Properties of River Networks. In AGU Fall Meeting Abstracts (Vol. 2019, pp. EP51C--2107). 